\title{
EL HALLAZGO DE LOS RESTOS PARCIALES DE UNA CUEVA ARTIFICIAL DE ENTERRAMIENTO CALCOLÍTICO EN EL YACIMIENTO ARQUEOLÓGICO DE GETSEMANÍ-CERRO DEL OJO (PEDRERA, SEVILLA)
}

\author{
THE DISCOVERY OF THE PARTIAL REMAINS OF AN ARTIFICIAL BURIAL CAVE OF THE COPPER \\ AGE IN THE ARCHAEOLOGICAL SITE OF GETSEMANÍ-CERRO DEL OJO (PEDRERA, SEVILLA)
}

\author{
JOSÉ MIGUEL BASCÓN MATEOS* \\ ISABEL MARÍA JABALQUINTO EXPÓSITO* \\ ÚRSULA TEJEDOR GARCÍA*
}

\begin{abstract}
Resumen: La intervención arqueológica desarrollada en el yacimiento arqueológico de "Getsemaní-Cerro del Ojo" (Pedrera, Sevilla) nos ha permitido documentar los restos parciales de una cueva artificial de enterramiento perteneciente a la Edad del Cobre. Así pues, en este trabajo se presentan y exponen los resultados obtenidos tras el estudio de este hallazgo que nos acerca al origen, evolución y muerte de las comunidades prehistóricas en la Sierra Sur sevillana.

Palabras clave: cueva artificial, enterramientos, Edad del Cobre.
\end{abstract}

\section{INTRODUCCIÓN, LOCALIZACIÓN Y DELIMITACIÓN DEL ÁREA DE INTERVENCIÓN}

La redacción del presente artículo surge como resultado de la actividad arqueológica preventiva (A.A. Prev. con Expd. No35/2012 AA.AA y Ref. DPPH/rg)

* Servicios Arqueológicos BM, c./Ecouflant, 5. 14546-Santaella (Córdoba). Correo-e: serviciosarqueologicosbm@gmail.com

\begin{abstract}
The archaeological actions carried out at "Getsemaní-Cerro del Ojo" Archaeological site (located in Pedrera, Sevilla) have enabled us to document partial remains of a man-made burial cave belonging to the Copper Age. Therefore, this work states and presents detailed results obtained from the research and study of this finding, which definitely gives us a closer look at the origin, evolution and death of prehistoric communities based in Seville southern mountains. Keywords: artificial cave, burials, Copper Age.
\end{abstract}

desarrollada ante las obras de remodelación y ampliación realizadas en las instalaciones de la S.C.A de aderezo Getsemaní. La zona de actuación en la que se han llevado a cabo los trabajos arqueológicos de excavación se encuentra ubicada en las inmediaciones del núcleo poblacional de Pedrera, más concretamente en la zona norte de dicha localidad, junto a la Carretera SE491 que une las poblaciones vecinas de Gilena y Pedrera, P.K. 8.0, en la provincia de Sevilla. La finca en la que se han proyectado estas labores posee una superficie total de $33.044 \mathrm{~m}^{2}$ y se inserta en el partido 
del Santo Cristo o Llano de Ojo, dentro del propio término municipal. En su franja norte y oeste linda con los terrenos de la cantera "Cerro del Ojo", al sur con la ya mencionada carretera SE-491 y al este con terrenos particulares en los que se sitúan pequeñas edificaciones que son utilizadas para distintos menesteres (fig. 1).

\section{DESCRIPCIÓN DE LOS RESTOS PARCIALES DE UNA CUERVA ARTIFICIAL DE ÉPOCA CALCOLÍTICA}

Desarrollando las pertinentes labores de excavación en el Área C, y a cierta distancia de donde estas se estaban efectuando, llamó poderosamente nuestra atención, tras una atenta prospección del terreno, un estrato de relleno de origen antrópico (U.E. 18) que colmataba con tierra rojiza lo que parecía ser, y finalmente fue, una interfacies vertical constructiva excavada artificialmente en el estrato margoso blanquecino (U.E. 2), y situada en un pequeño talud que se hallaba próximo a los ya existentes y operativos patios de fermentadores de la cooperativa olivarera (fig.2).

De este modo y siendo conscientes del tipo de hallazgos que en estos parajes podrían aparecer según la bibliografía manejada, procedimos a realizar una limpieza superficial de dicha zona; eliminando toda la vegetación que ocultaba y dificultaba su visión, para más tarde, comenzar con el vaciado del estrato margo-arcilloso de color rojizo (U.E. 18) originado como consecuencia de la destrucción, arrasamiento y posterior colmatación de la estructura funeraria en el momento de demolición parcial de la cueva en época contemporánea (fig. 3). En este estrato pudimos recuperar toda una serie de artefactos actuales tales como un enchufe, fragmentos de ladrillo, discos de radial, elementos de plástico, metal, etc... Esto nos confirmó que la cueva fue parcialmente arrasada en época contemporánea, más concretamente a partir de los años 90 del siglo $\mathrm{XX}$, mientras se procedía a la construcción del patio de fermentadores inmediatamente cercano a la zona en la que trabajábamos. Así pues, una vez eliminado por completo el estrato que colmataba los restos parciales y sesgados de la estructura funeraria, quedó a la vista aproximadamente una cuarta parte de lo que en origen hubiera sido un espacio hipogeo (cámara sepulcral) con cubierta plana o ligeramente abovedada de planta cuadrangular-rectangular, sección vertical hemisférica de paredes cóncavas, y suelo de ocupación convexo levemente irregular con buzamiento nortesur (fig. 4).
Esta cámara sepulcral, mutilada transversalmente como se dijo con anterioridad, posee unas dimensiones de 3'75 m en su eje transversal, un mínimo de $2 \mathrm{~m}$ en su eje anteroposterior (desconocemos el desarrollo total en su parte oeste) y una altura cercana a 1'90 m en su zona más alta. Su cota máxima se emplaza en los 489'70 m s.n.m. mientras que la mínima se sitúa en los 487'64 m s.n.m. (fig.5). En este sentido y teniendo en cuenta lo expuesto, la estructura funeraria documentada en el yacimiento arqueológico de Getsemaní-Cerro del Ojo podría enmarcarse dentro de varias de las tipologías establecidas en la obra de Encarnación Rivero Galán (Rivero 1986 y 1988).

Lo que sí que parece claro, ya que no conocemos si la entrada a dicha tumba se haría mediante acceso directo, pozo o corredor de entrada (tipologías I y II respectivamente), es que dicha estructura quedaría encuadrada en la tipología IV, dentro de la cual se agrupan todas aquellas que por no presentar una morfología clara (imprecisa en este caso por la destrucción parcial) no pueden ser incluidas en las otras tres existentes (Rivero 1988: 27).

Continuando con la descripción de esta cueva artificial, debemos señalar que en las paredes laterales que conforman el alzado de lo que conservamos de ella se abren, a distintas alturas del suelo y sobre lo que podríamos denominar como un "banco corrido o poyete" de unos 40-50 cm de altura (U.E. 40), una serie de nichos excavados en la roca marga (tres concretamente), que en lo sucesivo pasaremos a denominar como norte, sur y este por la proximidad que muestran con la orientación de los puntos cardinales. Dos de estos nichos (norte y este) se hallaban cegados por grandes bloques de roca caliza (UU.EE. 36 y 37 respectivamente) que se encontraban calzados por piedras de menor tamaño y que se situaban en la entrada apoyados sobre el "banco o poyete" (U.E. 40) al que hacíamos mención anteriormente; de ahí que hayamos podido interpretar que ambos se han mantenido intactos tras el momento de uso de los mismos (figs. 6 y 7). Por el contrario, no ocurre lo mismo con el tercero de los nichos (sur) ya que el nivel de arrasamiento detectado en él únicamente ha permitido recuperar una pequeña parte del mismo, por lo que la información que hemos podido extraer es significativamente menor.

Respecto a los distintos nichos hallados en la estructura hipogea descubierta en el yacimiento de Getsemaní-Cerro del Ojo podemos apuntar, además, la siguiente información (fig. 8):

Nicho norte (U.E. 21): Posee una planta de tendencia circular u ovalada y tiene unas dimensiones de 1'42 m 


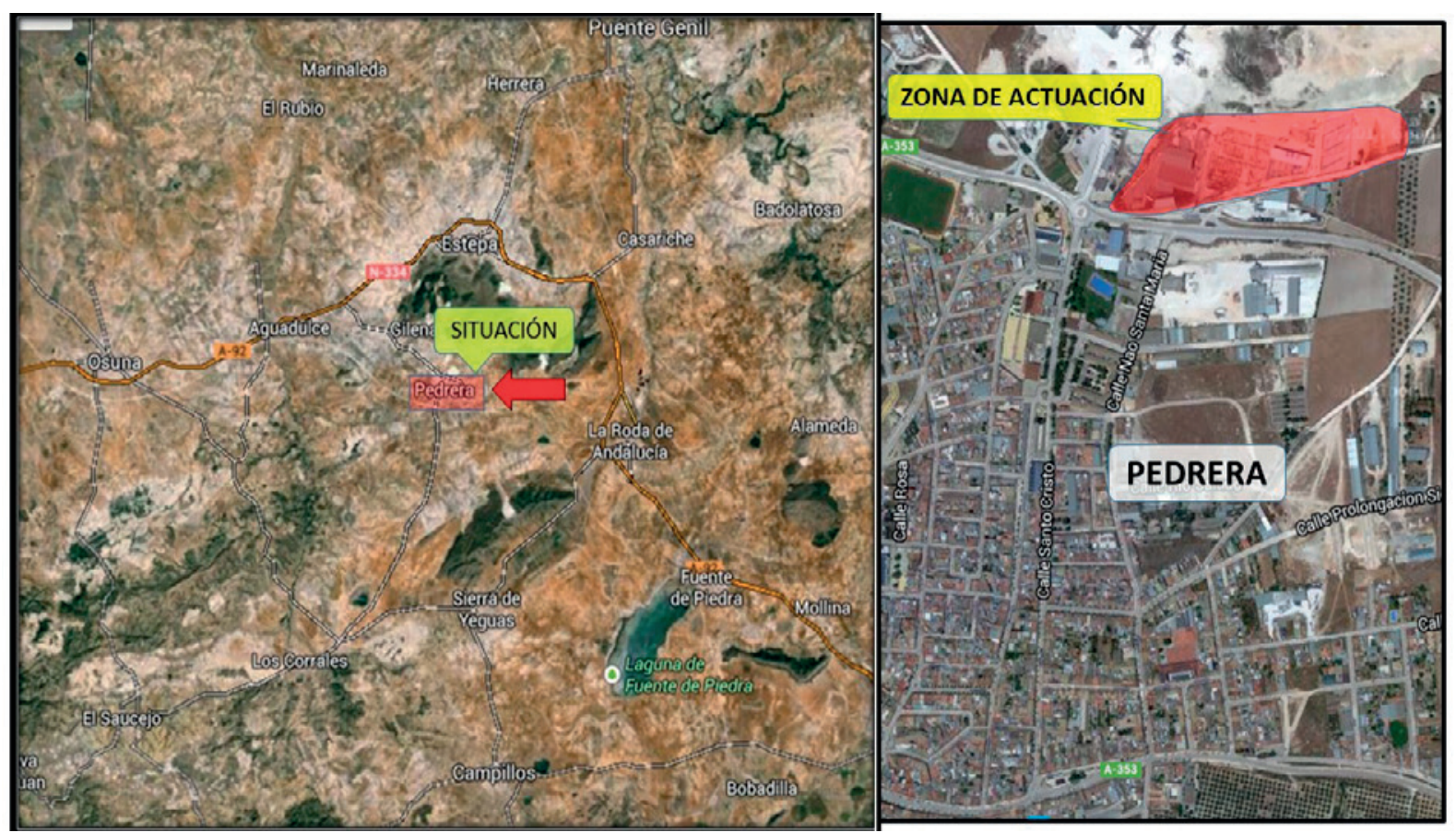

Figura 1: Situación y emplazamiento de la intervención arqueológica desarrollada en la S.C.A "Getsemaní".

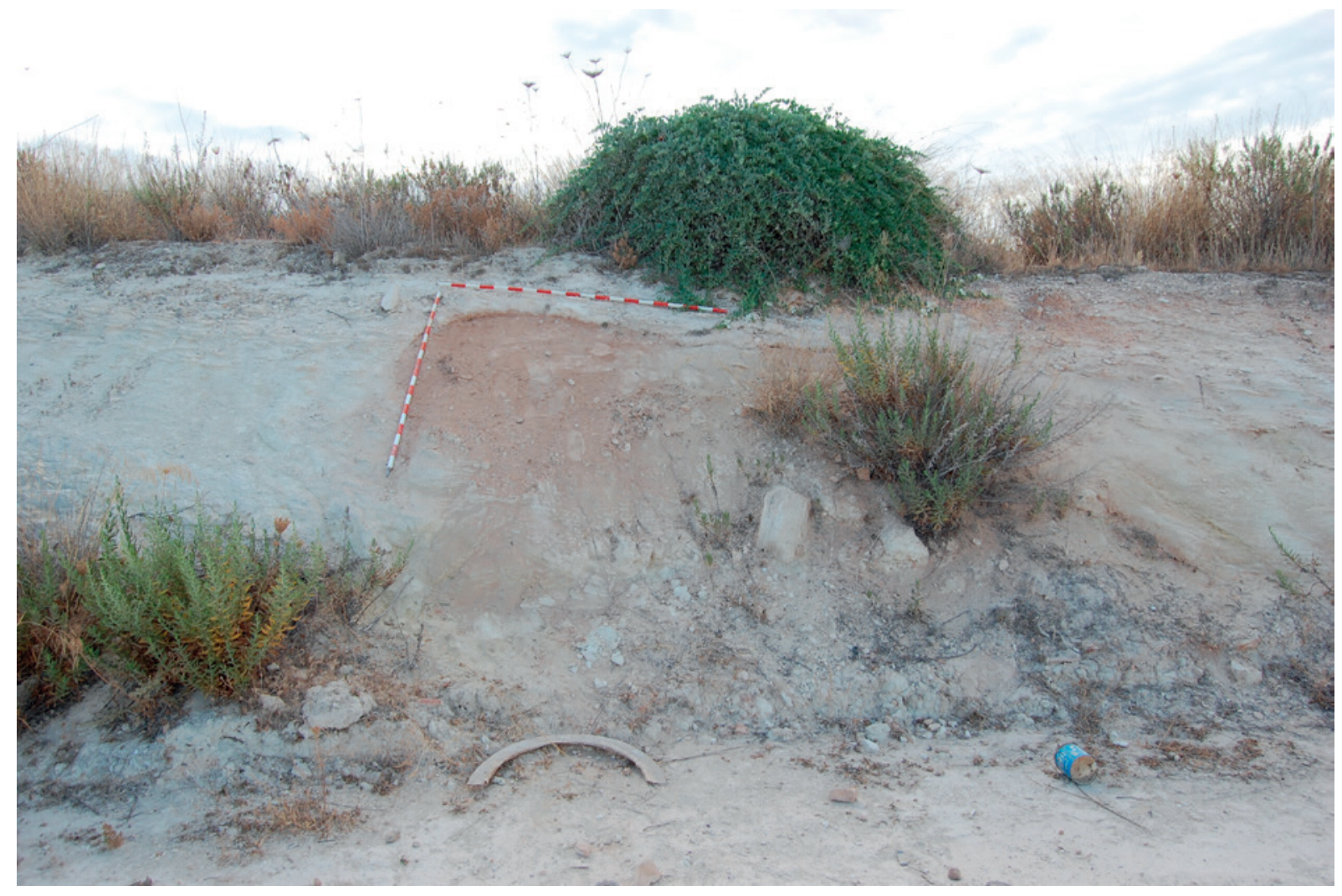

Figura 2: Vista en detalle del talud en el que se ocultaban los restos parciales de la cueva artificial excavada en el yacimiento arqueológico de Getsemaní-Cerro del Ojo.

ISSN: $1133-4525$ ISSN-e: 2255-3924 
Tabla 1: Distribución de restos óseos humanos hallados en el nicho norte.

\begin{tabular}{|l|c|c|}
\hline \multicolumn{1}{|c|}{ Región anatómica } & Hueso & Descripción conservación \\
\hline Cintura escapular & Clavícula & 1 fragmento \\
\hline Cintura pelviana & Coxal & 1 fragmento \\
\hline \multirow{2}{*}{ Extremidades superiores e inferiores } & Huesos largos (húmero, fémur y tibia) & 44 fragmentos \\
\cline { 2 - 3 } & Metacarpos & 4 fragmentos \\
\hline
\end{tabular}

en su eje transversal y 1'47 m en su eje anteroposterior (esto hace que posea una superficie que se sitúa en torno a los 1'56 $\mathrm{m}^{2}$ ) (fig. 9).

En cuanto a su alzado, hay que decir que posee una altura máxima de 0'78 m y su cubierta es abovedada. Su cota máxima y mínima son las siguientes: 489'10 m s.n.m. y 488'31 m s.n.m. Al igual que sucede en los demás nichos, sobre la superficie inferior de la interfacie (suelo) que conforma esta tumba norte (U.E. 21), se dispone un lecho formado por piedras calizas de diverso tamaño (U.E. 24) que se adaptan casi por completo a la superficie del nicho y sobre las que se depositan los restos óseos inhumados (U.E. 41) de un individuo de edad adulta. Algunas de las piedras que conforman este lecho, dos concretamente, conservan un intenso color rojo-anaranjado, fruto de la aplicación de un pigmento elaborado principalmente a base de mineral de cinabrio (U.E. 34) y cuya utilización podría interpretarse como un elemento decorativo, funcional (al poder ser utilizado como agente antiséptico) o cultual al estar asociado al rito funerario (la preparación de este pigmento a partir de mineral de cinabrio ha quedado suficientemente demostrada gracias al estudio de caracterización de materiales realizado por D. Álvaro Caballero Amores, Profesor-Doctor del Departamento de Química Inorgánica e Ingeniería Química de la Universidad de Córdoba).

Las medidas de este lecho norte serían las siguientes: 1'42 $\mathrm{m}$ en su eje trasversal (ocupa todo el espacio que ofrece la excavación del nicho) por 1'02 m en su eje anteroposterior. Además, sus cotas máxima y mínima respectivamente son las que siguen: $488^{\prime} 47 \mathrm{~m}$ s.n.m. y 488'26 m s.n.m. Respecto a los restos óseos que descansaban en este nicho (Individuo 1, U.E. 41), se debe indicar que se han documentado un total de cincuenta fragmentos de huesos pertenecientes a un individuo de edad adulta. Esta interpretación se debe a la ausencia de líneas de crecimiento visibles y por la madurez ósea que estos presentan. El sexo, pese a contar con restos pertenecientes a la pelvis, no ha podido determinarse con fiabilidad ya que estos están muy fragmentados. Los restos óseos exhumados de este nicho quedarían identificados de la siguiente manera (tabla 1).

Sobre ellos debemos señalar que no se hallaron en conexión anatómica, ya que se encontraban simplemente acumulados sobre el lecho de piedra, aunque prestando mayor cuidado en la colocación de los huesos largos. Interpretamos que su inhumación es de tipo secundario, es decir, el resultado de un proceso cultural mediante el cual el esqueleto, una vez desarticulado, es enterrado nuevamente colocando sus unidades anatómicas de manera tal que difieren de la posición y ubicación original. Así pues, el hecho de hallar los restos óseos agrupados sin evidencias de articulación unido a la ausencia de muchos de los huesos que componen el esqueleto humano, hace posible que podamos plantear la hipótesis de que los restos fueron introducidos en la sepultura procedentes de otros espacios en los que previamente habrían sido depositados (osario) o también, que se procediera a su inhumación una vez que los cuerpos hubieran perdido sus tejidos blandos. Esta idea, defendida por algunos investigadores (Furgús 1937: 55), se relacionaría con la existencia de un ritual consistente en pintar los huesos de color rojo ocre antes de proceder a su depósito en la tumba (aunque los huesos recuperados en este nicho no conserven restos de pigmentación en rojo cinabrio no ocurre de igual forma con los restos óseos hallados en los otros dos nichos documentados. Más adelante, en el capítulo dedicado a síntesis y conclusiones, hablaremos de las distintas teorías existentes al respecto). Asimismo, los restos óseos exhumados de este nicho no presentaban una orientación significativa, por lo que interpretamos que la deposición de los restos fue realizada sin atender a una alineación concreta.

Por último, cabe destacar también que colocado junto al cuerpo inhumado, sobre el lecho de piedra, se localizó el único elemento de ajuar que ha sido recuperado durante el proceso de excavación llevado a cabo en esta la estructura funeraria. Se trata de una gran 


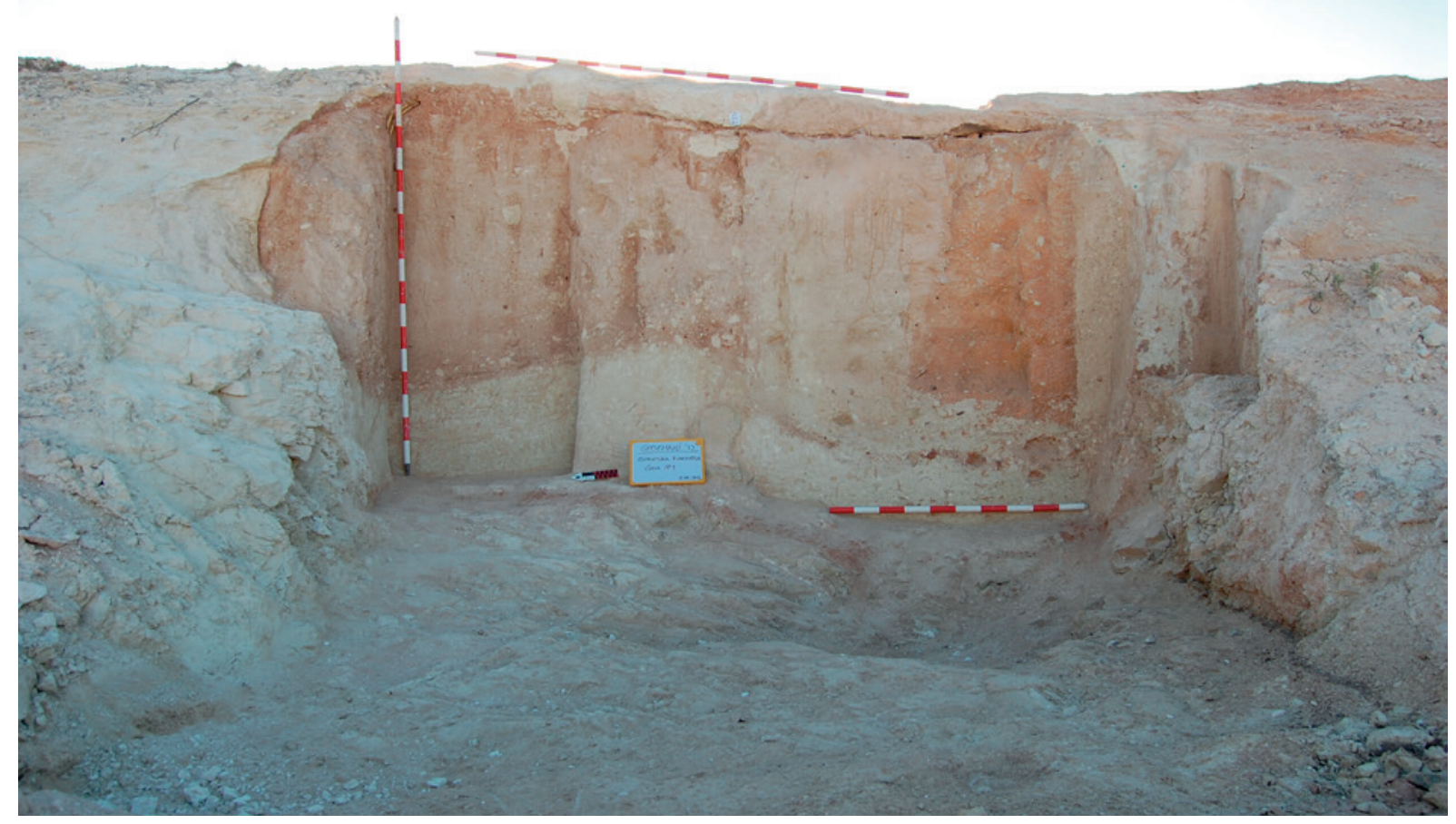

Figura 3: Vista general de la cueva artificial una vez excavado parcialmente el estrato de relleno (U.E 18) que colmataba la estructura funeraria.

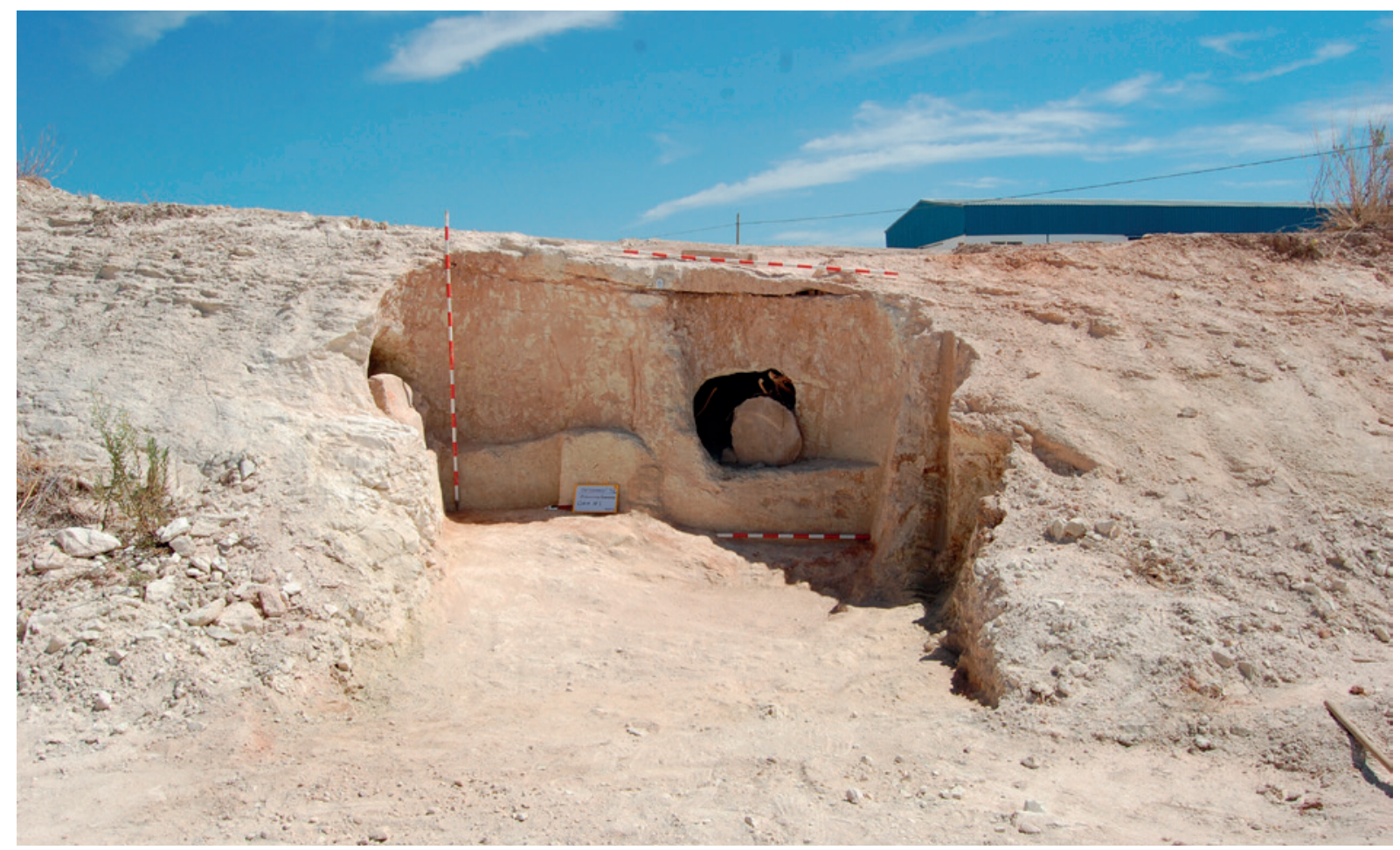

Figura 4: Vista general de la cueva artificial una vez descubiertos los nichos norte, este y sur. 
Tabla 2: Distribución de los restos óseos humanos hallados en el nicho sur.

\begin{tabular}{|l|c|c|}
\hline \multicolumn{1}{|c|}{ Región anatómica } & Hueso & Descripción conservación \\
\hline Cintura escapular & Clavícula & 1 fragmento \\
\hline Columna vertebral & Vértebras & 2 fragmentos \\
\hline \multirow{2}{*}{ Extremidades superiores e inferiores } & Huesos largos & 18 fragmentos \\
\cline { 2 - 3 } & Metacarpos-metatarsos-falanges & 7 fragmentos \\
\hline
\end{tabular}

lámina de sílex completa y sin retocar que funcionaria a modo de cuchillo y que posee en uno de sus filos posibles marcas asociadas a su uso como tal. La pieza en cuestión, que conserva restos de pigmentación en rojo cinabrio al igual que algunas de las piedras que componían el lecho sobre el que descansaba, posee un tamaño de $16 \mathrm{~cm}$ de largo por $2 \mathrm{~cm}$ de ancho máximo y ha sido tallada a dos filos no dejando entre uno y otro lo que se denomina como cresta, sino un espacio liso y sin tallar de sección trapezoidal (fig. 10). Resulta ciertamente extraño no haber hallado ningún elemento de ajuar más vinculado con el resto de cuerpos inhumados en los distintos nichos que componen la tumba, por lo que planteamos la hipótesis de que, salvo excepción, el grueso de estos elementos asociados con el ritual funerario se encontraran depositados en la cámara principal de la estructura hipogea y hayan sido saqueados en el momento en el que se produjo el arrasamiento parcial y la posterior colmatación de la cueva.

Nicho sur (U.E. 23): Como ya se dijo con anterioridad, los restos de este nicho se encontraron parcialmente destruidos por la interfacies de arrasamiento transversal (U.E. 20) que originó la existencia del talud, bajo el cual se halló la estructura funeraria (su fase de arrasamiento coincide con la de destrucción parcial de la cámara sepulcral), por lo que pocos datos podemos aportar sobre su morfología y estructura (fig. 11). En origen poseería una planta semicircular con una sección vertical hemisférica de paredes cóncavas y cubierta abovedada, aunque únicamente hemos podido recuperar algo menos de la mitad al conservar 0'80 m en su eje anteroposterior, 1'10 $\mathrm{m}$ en su eje transversal (superficie próxima a $0^{\prime} 57 \mathrm{~m}^{2}$ ) y $0^{\prime} 82 \mathrm{~m}$ de altura máxima. Sus cotas máxima y mínima son 488'66 m s.n.m. y 487'83 m s.n.m. respectivamente.

Al igual que ocurriera con el nicho norte, en la superficie baja de la tumba se sitúa un lecho de piedras calizas de diversos tamaños, también pintadas con cinabrio (U.E. 34), sobre las cuales descansarían los restos óseos del individuo inhumado en ella. Las dimensiones conservadas del lecho en cuestión (U.E. 28) serían las que siguen a continuación: 0'80 m de eje anteroposterior y 0'90 m de eje transversal (superficie de 0’34 $\mathrm{m}^{2}$ aproximadamente) situándose su cota máxima en 487'93 m s.n.m. mientras que la mínima se emplaza en los $487^{\prime} 83$ m s.n.m. Sobre el nicho, revueltos entre el estrato que colmataba gran parte de la estructura funeraria (U.E. 18), se hallaron un total de veintiocho pequeños fragmentos de restos óseos (Individuo 3, U.E. 45) que quedarían identificados según se muestra en la tabla 2.

En contraposición a los restos óseos hallados en el nicho norte, estos sí que presentaban abundantes restos de pigmentación en rojo cinabrio (U.E. 35). Tal es así que, entremezclados entre los huesos y el estrato que los cubría (U.E. 18), pudimos recuperar distintas muestras granuladas de pigmento, que más tarde fueron analizadas y han aportado unas interesantes conclusiones acerca de su naturaleza, composición y caracterización (UU.EE. 34 y 35 ).

Nicho este (U.E. 22): Este nicho se constituye como el más amplio de todos cuantos hemos localizado en la estructura hipogea. Tal es así que, diferenciándose de lo que sucediera en los nichos norte y sur, en su interior encontramos tres lechos realizados de nuevo a base de piedras calizas de variado tamaño, sobre los que se localizan diversas inhumaciones (estamos, por tanto, ante un nicho colectivo). Dos de estos lechos, los que consideramos principales, se sitúan en la parte norte y sur del nicho mientras que el tercero de ellos, más pequeño y de construcción más descuidada, se dispone al fondo y en un segundo plano, en la zona oriental del mismo (fig. 12). Al igual que ocurriera con el nicho norte, su planta es de tendencia circular u ovalada presentando unas dimensiones de 2'32 m en su eje transversal y 2'29 m en el eje anteroposterior (esto hace que el nicho posea una superficie próxima a los 3'50 $\mathrm{m}^{2}$ ). Su sección vertical es hemisférica de paredes 


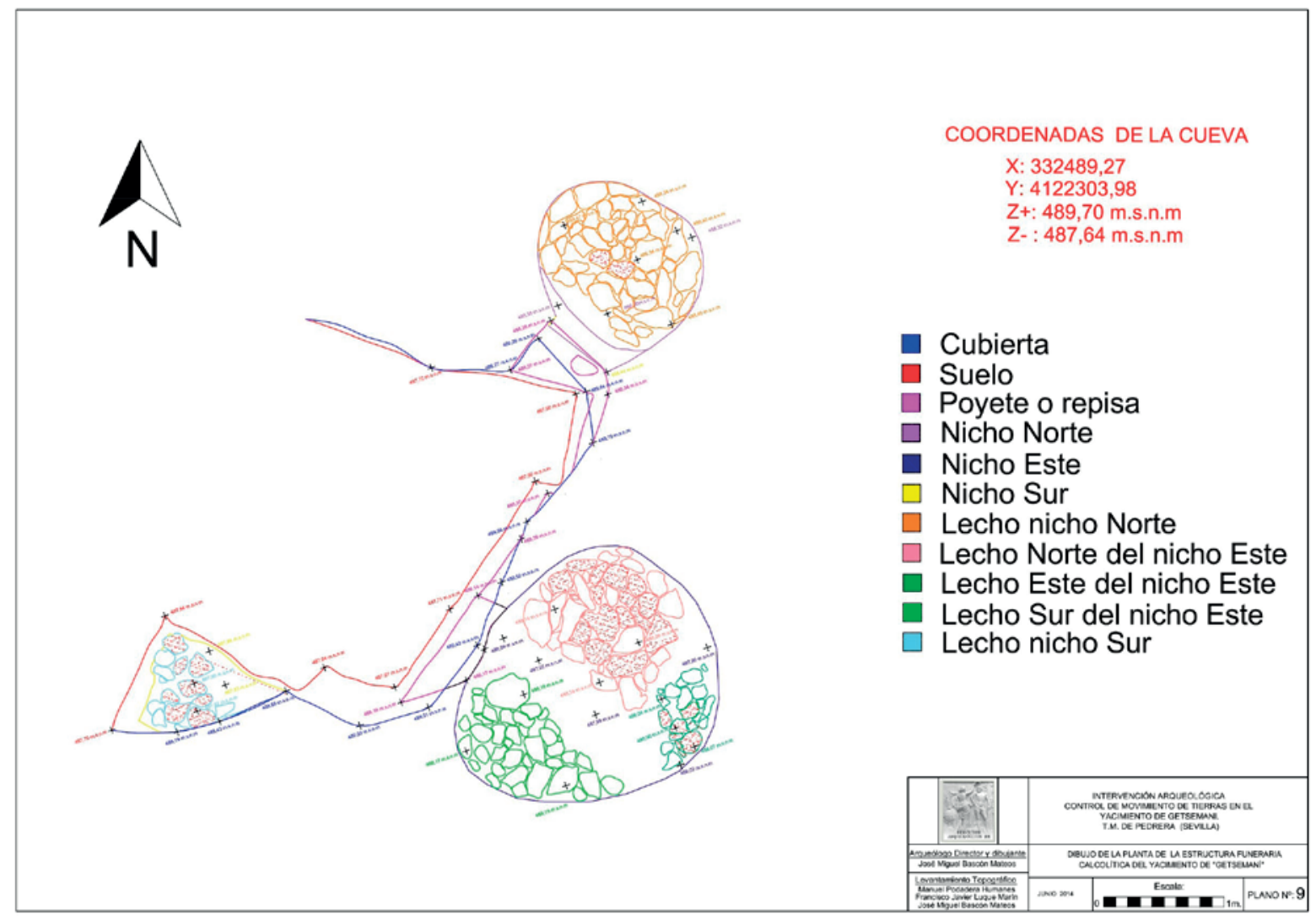

Figura 5: Dibujo en planta de la cueva artificial calcolítica hallada en el yacimiento arqueológico de Getsemaní-Cerro del Ojo.

cóncavas, presentando una cubierta abovedada que llega a alcanzar 1'10 m de altura. Sus cotas máxima y mínima son las siguientes: 489'08 m s.n.m. y 487'92 m s.n.m. La superficie, cotas y medidas de los diversos lechos que conforman este nicho son las que se especifican a continuación:

Lecho norte (U.E. 25): Posee 1'23 m en su eje anteroposterior y 1'19 m en su eje transversal, por lo que configuraría una superficie próxima a $1^{\prime} 10 \mathrm{~m}^{2}$. Sus cotas máxima y mínimas son 488'24 m s.n.m. y 487'92 m s.n.m. Como ya sucediera con el nicho norte y sur, algunas de las piedras que conforman este lecho conservan un color ocre rojizo fruto de haber sido pintadas con pigmento elaborado a partir de mineral de cinabrio (fig. 13).

Respecto a los restos óseos hallados sobre este lecho (Individuo 2.1, U.E. 42) podemos indicar que se ha logrado recuperar un total de ciento sesenta fragmentos de hueso que quedan identificados de la siguiente manera en la tabla 3.
Como ya sucediera con los anteriores esqueletos excavados, los restos óseos hallados en este nicho no presentaban una alineación determinada, por lo que suponemos que la deposición de los restos fue realizada sin atender a una orientación establecida. Del mismo modo, tampoco se hallaron en conexión anatómica, ya que se encontraban acumulados de forma imprecisa sobre el lecho de piedra. Interpretamos, por tanto, que su inhumación es de tipo secundario aunque, como ocurre en las demás inhumaciones y debido a diferentes causas postdeposicionales, no descartamos otras posibilidades que pasaremos a explicar con posterioridad en el capítulo de síntesis y conclusiones. Se debe destacar que algunos de estos huesos presentan una parcial y leve coloración en rojo cinabrio.

Los restos pigmentados pertenecen a restos del maxilar superior, un cúbito, un humero, algunas vertebras, partes del sacro y cóccix, así como tres fragmentos indeterminados.

Por último, del estudio antropológico realizado sobre los restos óseos exhumados podemos deducir que, según las características morfológicas que se aprecian 
Tabla 3: Distribución de los restos óseos humanos hallados en el lecho norte del nicho este. Individuo 2.1 (fig. 14. 2c).

\begin{tabular}{|c|c|c|}
\hline Región anatómica & Huesos & Descripción conservación \\
\hline \multirow[t]{2}{*}{ Cráneo } & $\begin{array}{l}\text { Frontal izquierdo, parietales, } \\
\text { occipital, temporal izquierdo }\end{array}$ & \multirow[t]{2}{*}{ Plurifragmentación } \\
\hline & Maxilar superior y mandíbula & \\
\hline \multirow{4}{*}{$\begin{array}{l}\text { Cintura } \\
\text { escapular }\end{array}$} & Clavícula derecha & 1 fragmento (extremos ausentes) \\
\hline & Clavícula izquierda & 2 fragmentos (extremos ausentes) \\
\hline & Escápula derecha & 2 fragmentos \\
\hline & Escápula izquierda & 1 fragmento \\
\hline \multirow{6}{*}{$\begin{array}{l}\text { Extremidades } \\
\text { superiores }\end{array}$} & Húmero derecho & Incompleto en parte distal \\
\hline & Cúbito derecho & Incompleto en parte proximal \\
\hline & Húmero izquierdo & Ausencia de cabeza humeral \\
\hline & Cúbito izquierdo & Incompleto en parte distal \\
\hline & Radio izquierdo & Incompleto en parte distal \\
\hline & Carpos- Metacarpos- Falanges & $\begin{array}{l}\text { Hueso grande (izqdo.), seis metacarpos y cuatro falanges (dos } \\
\text { proximales-dos mediales) }\end{array}$ \\
\hline \multirow[t]{2}{*}{ Costillas } & Costillas & $\begin{array}{l}\text { Plurifragmentación. } \\
8 \text { fragmentos (lateralidad derecha) } \\
2 \text { fragmentos (lateralidad izquierda) }\end{array}$ \\
\hline & Esternón & 1 fragmento (perteneciente al cuerpo) \\
\hline \multirow{4}{*}{$\begin{array}{l}\text { Columna } \\
\text { vertebral }\end{array}$} & Vértebras cervicales & 7 cuerpos vertebrales \\
\hline & Vértebras dorsales & 4 fragmentos \\
\hline & Vértebras lumbares & 2 cuerpos vertebrales y plurifragmentación \\
\hline & Vértebras sacras & 2 fragmentos \\
\hline Cintura pélvica & Coxal derecho e izquierdo & Incompletos \\
\hline \multirow{5}{*}{$\begin{array}{l}\text { Extremidades } \\
\text { inferiores }\end{array}$} & Fémur derecho & Fragmentación de epífisis proximal y ausencia de epífisis distal \\
\hline & Tibia derecha & Ausencia de epífisis proximal \\
\hline & Fémur izquierdo & Epífisis proximal y distal fragmentadas \\
\hline & Tibia izquierda & Epífisis proximal y distal ausentes \\
\hline & Carpos- Metacarpos- Falanges & $\begin{array}{l}\text { Calcáneo, astrágalo y cuneiforme lateral derechos presentes. } \\
\text { Cinco metatarsos del pie derecho y una falange proximal }\end{array}$ \\
\hline
\end{tabular}

en la pelvis y en el cráneo (Workshop of European Anthropologists 1980; Ubelaker 1989; Data Collection Codebook 2006 y, más recientemente, el texto coordinado por Serrulla 2013), los restos asociados al individuo inhumado en el lecho norte del nicho este (Individuo 2.1) corresponden a un varón cuya edad, a partir del estudio de la sínfisis del pubis (Todd 1921), se sitúa entre los 30-35 años.
Lecho sur (U.E. 27): Realizado también con piedra caliza de diversos tamaños, este lecho tiene unas dimensiones de 1'50 m en su eje anteroposterior y 0'80 m de eje transversal, conformándose, por tanto, una superficie cercana a los 0'75 $\mathrm{m}^{2}$. Su cota máxima es de 488'18 m s.n.m. y la mínima de 487'92 m s.n.m. Como excepción, este lecho es el único que no alberga piedras con restos de pigmentación en ocre rojizo. 
Figura 6: Vista en detalle del exterior del nicho norte cegado por la piedra que impedía la entrada.

Figura 7: Vista en detalle del exterior del nicho este con la piedra que imposibilitaba su acceso.
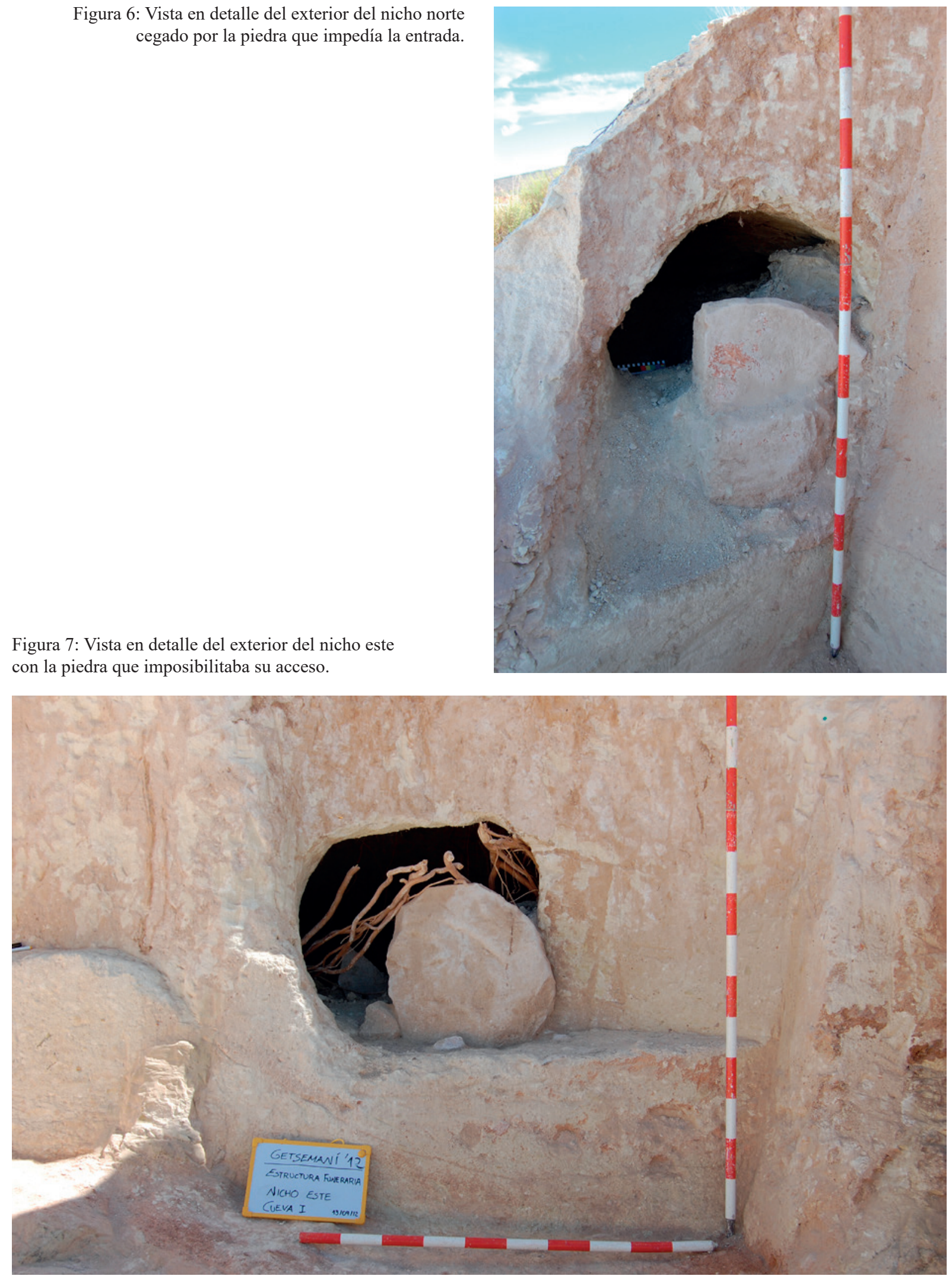

ISSN: 1133-4525 ISSN-e: 2255-3924 
Tabla 4: Distribución de los restos óseos humanos hallados en el lecho sur del nicho este. Individuo 2.3. (Fig. 15. 2c)

\begin{tabular}{|c|c|c|}
\hline Región anatómica & Huesos & Descripción conservación \\
\hline \multirow{2}{*}{ Cráneo } & $\begin{array}{l}\text { Hemifrontal y parietal derecho. Occipital. } \\
\text { Hemimaxilar superior izquierdo }\end{array}$ & Plurifragmentación \\
\hline & Mandíbula & Ausencia del cóndilo izquierdo \\
\hline Cintura escapular & Clavícula izquierda & 1 fragmento (extremos ausentes) \\
\hline \multirow{6}{*}{$\begin{array}{l}\text { Extremidades } \\
\text { superiores }\end{array}$} & Húmero derecho & 1 fragmento del tercio distal \\
\hline & Cúbito derecho & Epífisis proximal y distal ausentes \\
\hline & Radio derecho & Ausencia de parte proximal y apófisis estiloides \\
\hline & Húmero izquierdo & Ausencia de parte proximal \\
\hline & Cúbito izquierdo & 1 fragmento de epífisis distal \\
\hline & Radio izquierdo & Epífisis proximal y distal ausentes \\
\hline Costillas & Costillas & $\begin{array}{l}\text { Plurifragmentación. } \\
2 \text { fragmentos (lateralidad derecha) } \\
3 \text { fragmentos (lateralidad izquierda) }\end{array}$ \\
\hline \multirow{2}{*}{$\begin{array}{l}\text { Columna } \\
\text { vertebral }\end{array}$} & Vértebras dorsales & 7 fragmentos \\
\hline & Vértebras lumbares & 4 cuerpos vertebrales \\
\hline Cintura pélvica & Coxal derecho & 1 fragmento \\
\hline \multirow{6}{*}{$\begin{array}{l}\text { Extremidades } \\
\text { inferiores }\end{array}$} & Fémur derecho & Fragmentación de epífisis proximal y de epífisis distal \\
\hline & Tibia derecha & Pérdida del tercio distal \\
\hline & Peroné derecho & Ausencia de epífisis distal \\
\hline & Fémur izquierdo & 1 fragmento (extremo distal) \\
\hline & Tibia izquierda & 2 fragmentos (epífisis proximal y maléolo medial) \\
\hline & Peroné izquierdo & 1 fragmento diafisario \\
\hline
\end{tabular}

Del cuerpo inhumado en este lecho (Individuo 2.3, U.E. 44) hemos podido recuperar un total de treinta $y$ ocho huesos correspondientes a (tabla 4).

En lo que respecta a la posición y orientación en la que se encontraron los restos óseos de este nicho, se debe indicar que se hallaban colocados también de forma desorganizada sobre el lecho de piedra, sin presentar una orientación ni deposición articulada que nos lleve a interpretar que se trata de una inhumación primaria.

Por otro lado, al igual que sucediera con los huesos exhumados del nicho norte, no se observa pigmentación alguna en los restos óseos hallados aquí. Tampoco en las piedras que componen la cama sobre la que se localizaron los restos de este individuo (2.3) se encontraron o conservaron restos de rojo cinabrio. Como sucede también en muchos de los huesos exhumados de los diferentes nichos excavados en la estructura funeraria de Getsemaní-Cerro del Ojo, hemos encontrado fracturas transversales de las diáfisis que, según los resultados obtenidos del estudio antropológico de los restos óseos, son de origen tafonómico y están causadas por alteraciones ambientales, quedando descartada, de este modo, la hipótesis inicial que nos hacía plantearnos una posible amputación de miembros por efectos rituales.

Ya por último, podemos indicar que los restos asociados al individuo 2.3 pertenecen a una persona de edad adulta que presentaba en sus huesos una importante gracilidad.

En cuanto al sexo, pese a conservarse un fragmento de la escotadura ciática del coxal derecho, no ha podido 


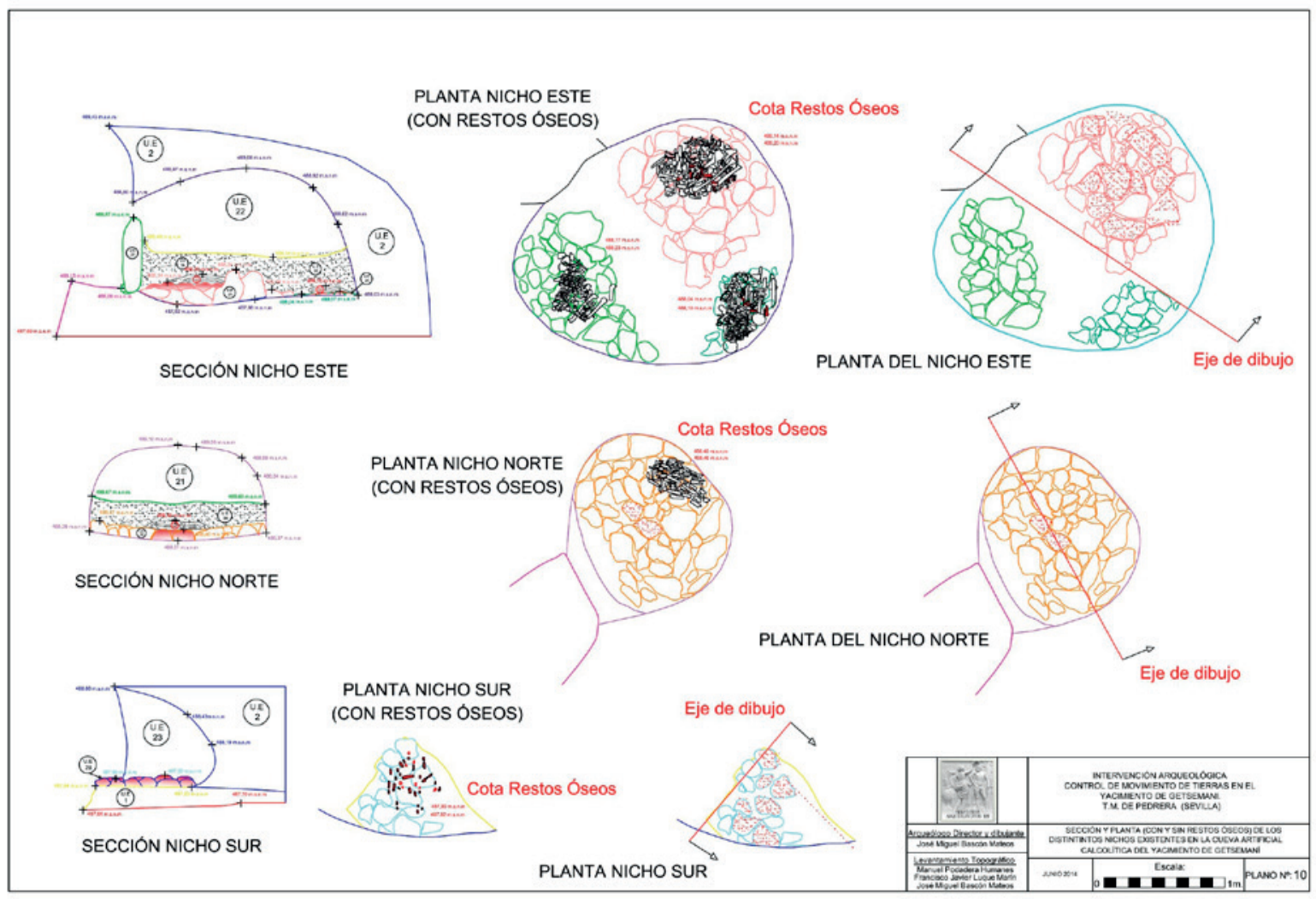

Figura 8: Sección y planta (con y sin restos óseos humanos) de los distintos nichos existentes en la cueva artificial calcolítica del yacimiento arqueológico de Getsemaní-Cerro del Ojo.

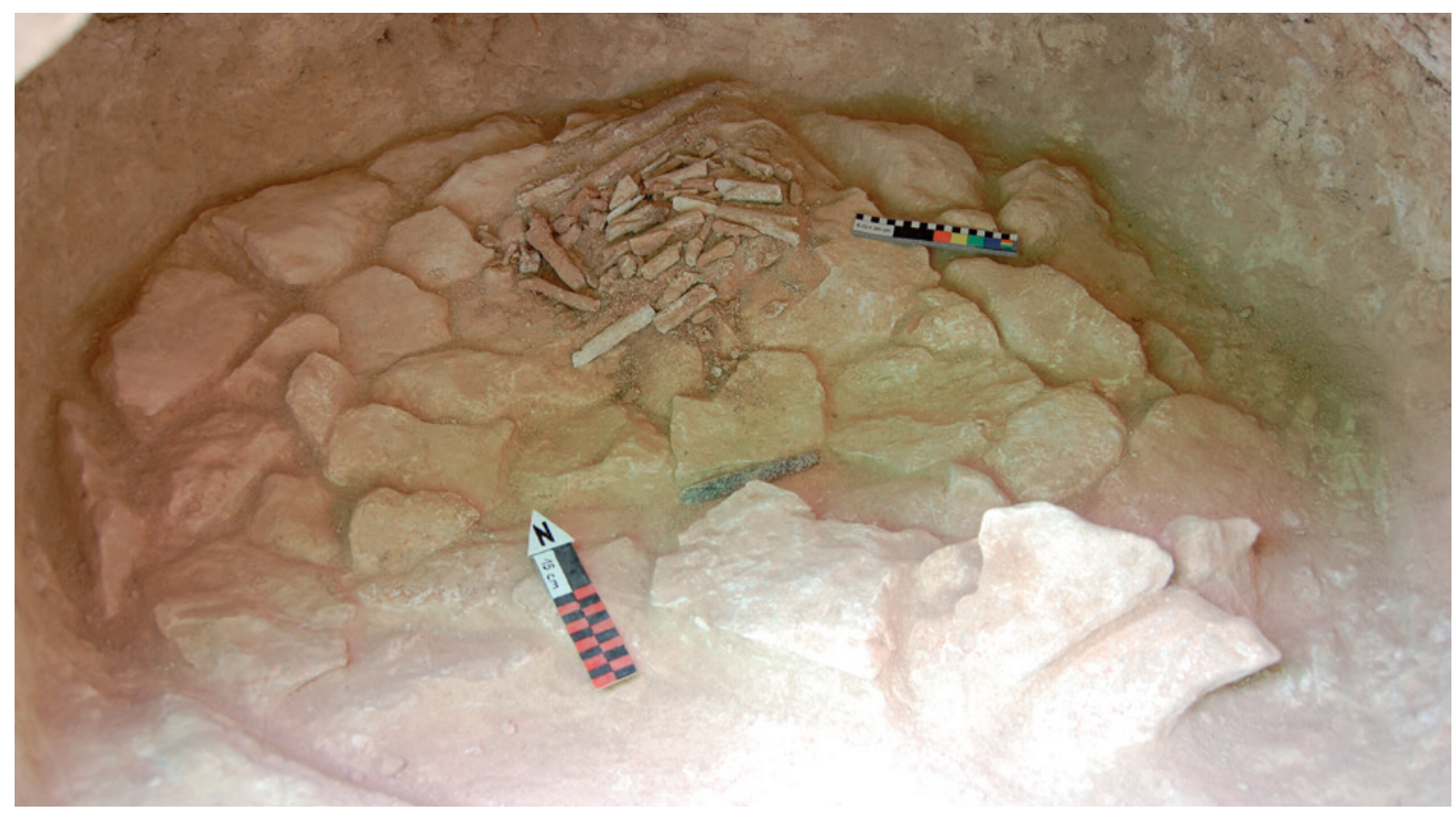

Figura 9: Interior del nicho norte completamente excavado. 
Tabla 5: Distribución de los restos óseos hallados en el lecho oriental del nicho este. Individuos 2.2.

\begin{tabular}{|c|c|c|}
\hline Región anatómica & Huesos & Descripción conservación \\
\hline \multirow{6}{*}{ Cráneo } & Parietales & $\begin{array}{l}\text { Fragmentos asociados a dos huesos parietales derechos y dos huesos } \\
\text { parietales izquierdos }\end{array}$ \\
\hline & Frontal & Un hueso frontal completo \\
\hline & Occipital & Plurifragmentación \\
\hline & Temporal & 1 fragmento \\
\hline & Maxilar & 1 fragmento de hemimaxilar superior izquierdo \\
\hline & Mandíbula & 2 fragmentos \\
\hline \multirow{4}{*}{$\begin{array}{l}\text { Extremidades } \\
\text { superiores }\end{array}$} & Húmeros & 10 fragmentos pertenecientes a dos húmeros de cada lateralidad \\
\hline & Cúbito & 7 fragmentos \\
\hline & Radio & 7 fragmentos asociados a dos radios izquierdos \\
\hline & Vértebras lumbares & 3 vértebras \\
\hline Cintura pélvica & Coxales & 5 fragmentos \\
\hline \multirow{3}{*}{$\begin{array}{l}\text { Extremidades } \\
\text { inferiores }\end{array}$} & Fémur & 11 fragmentos \\
\hline & Tibia & 6 fragmentos \\
\hline & Peroné & 5 fragmentos \\
\hline
\end{tabular}

determinarse de forma fiable debido al importante estado de fragmentación que presenta.

Lecho este (U.E. 26): Situado al fondo y en un plano secundario, este lecho está constituido por piedras de menor tamaño que los dos anteriores. De igual forma, sus dimensiones también son manifiestamente menores alcanzando 0'50 m en su eje anteroposterior y 0'95 $\mathrm{m}$ su eje transversal (superficie próxima a los $0^{\prime} 25 \mathrm{~m}^{2}$ ). Sus cotas máxima y mínima son 488’07 m s.n.m. y 487'98 m s.n.m. respectivamente. Se debe destacar de nuevo que algunas de las piedras que se constituyen como base para la deposición de los restos óseos inhumados, conservan restos de pigmentación ocre cinabrio (U.E. 34).

Los restos óseos (Individuos 2.2, U.E. 43) que se han conservado en este lecho oriental se corresponden con los siguientes huesos del esqueleto humano (tabla 5).

El apunte más reseñable del estudio de los huesos procedentes de la acumulación este ha sido la asociación de estos a un mínimo de dos individuos de edad adulta, de entre 17-25 años.

Este número mínimo de individuos se ha podido determinar gracias a la identificación, con seguridad, de restos pertenecientes a dos cráneos, cuatro húmeros (fig. 16) y dos radios (fig. 17), estos últimos presentando la misma lateralidad. Resulta interesante cómo sobre este pequeño lecho de construcción descuidada, que se sitúa al fondo y en un segundo plano del nicho (es el menor de todos los documentados en la cueva artificial de Getsemaní-Cerro del Ojo), se halla dispuesto más de un cuerpo. Interpretamos, por tanto, que su colocación en este lugar, al igual que queda documentado en numerosos enterramientos en cuevas artificiales, es fruto del desplazamiento hacia el fondo de los huesos que, en un momento dado, ocuparon los dos lechos principales que conforman el nicho este, solucionando, de este modo, una más que probable falta de espacio en la tumba. Por tanto, la colocación que estos restos presentaban en el momento en el que se procedió a su excavación no se correspondía, en absoluto, con la que podría mantener una inhumación en posición primaria, ya que se encontraban acumulados de forma aleatoria sobre el lecho de piedra sin mantener tampoco una orientación concreta y establecida. Estas inhumaciones, originadas como hemos apuntado anteriormente por el transporte procedente de los dos lechos principales que configuran este nicho oriental, sí que pueden ser interpretadas como secundarias con total seguridad, configurándose este lecho en sí mismo 
como el único enterramiento colectivo existente en este espacio funerario. En cuanto al sexo de los individuos aquí inhumados, podemos apuntar que de uno de los cráneos se ha conservado un frontal de características gráciles, lo que puede indicar la posibilidad de que este pertenezca a una mujer.

Por otro lado, entre los restos conservados se encuentran también cinco fragmentos de pelvis. En dos de ellos, de distinta lateralidad, puede observarse una parte de la escotadura ciática que, por sus características físicas, podrían asociarse a un posible varón. Ya por último, se debe reseñar que de este conjunto son escasos los huesos que presentan pigmentación en ocre cinabrio (vertebra, falange).

\section{SÍNTESIS Y CONCLUSIONES}

La intervención arqueológica desarrollada en el yacimiento arqueológico de Getsemaní-Cerro del Ojo nos ha permitido documentar la existencia de los restos parciales de una cueva artificial de enterramiento perteneciente al periodo Calcolítico. El hallazgo en cuestión,

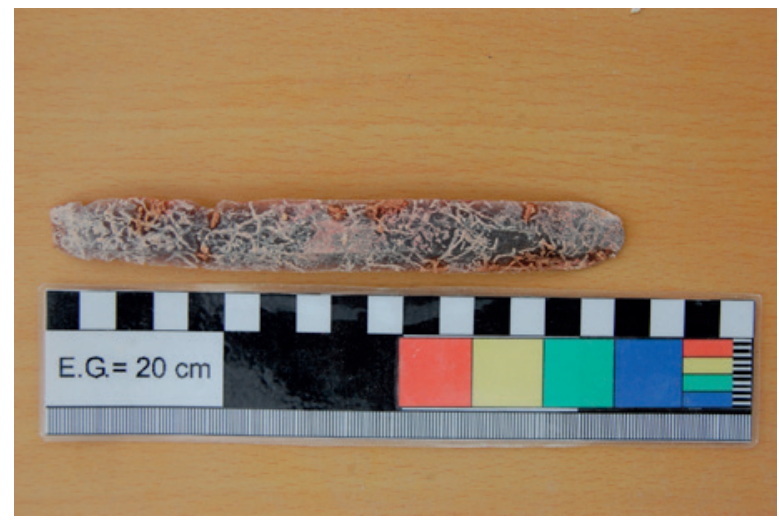

Figura 10: Gran lámina de sílex hallada sobre el lecho de piedra existente en el interior del nicho norte.

lejos de manifestarse aislado e imprevisto, se muestra en concordancia con otros descubrimientos realizados en la zona que, si bien no fueron excavados ni estudiados como hubiera sido deseable, sí que nos mostraban una clara y evidente huella de la actividad humana desarrollada en estos parajes que se emplazan entre la sierra y la campiña sur sevillana.

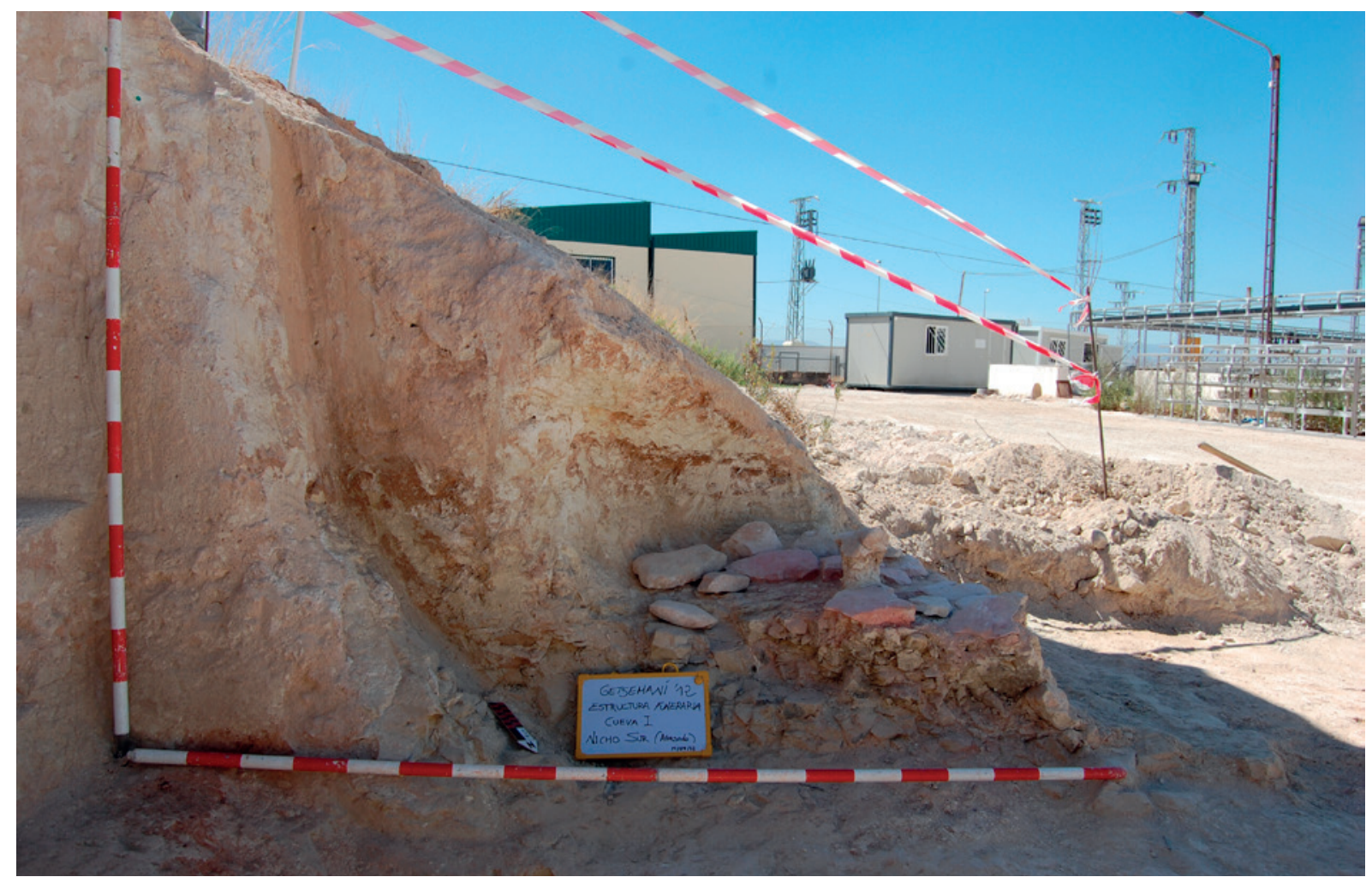

Figura 11: Restos parciales del nicho sur completamente excavado (en él se aprecia con suma claridad el corte transversal que arrasaba la estructura funeraria)

ISSN: 1133-4525 ISSN-e: 2255-3924 
De este modo, la ubicación de estas tierras, con predominio de terrenos terciarios de composición margosa que permiten la creación de este tipo de estructuras fúnebres (Pajuelo et al.2013: 290), en una de las vías naturales que ponen en comunicación la baja y alta Andalucía demuestra y hace posible una ocupación de comunidades social y culturalmente heterogéneas (García 2013: 50-51; García Rivero 2009: 239-240; Nocete 2001; Fabián 1995: 131), que mantienen en algunos de sus espacios de enterramiento (cuevas artificiales) ciertas analogías, que para nada deben resultar triviales e improvisadas. Además, su cercanía con el río Genil hace que este lugar se configure como un excelente punto estratégico que permite enlazar fácilmente con las fértiles tierras y centros de producción agrícola-ganadera del Valle del Guadalquivir por un lado (García 2013: 36-41) y con las altas tierras granadinas y sierras Subbéticas de otro, las cuales funcionaban, especialmente, como centros proveedores de materias primas relacionadas con la explotación y manufactura de los recursos líticos (Juárez 2010: 19; Nocete 2001).

Ya en los años 80 del pasado siglo se recogían en la bibliografía algunas referencias sobre estos hallazgos, acaecidos en el año 1978 en la zona denominada como Cerro del Ojo (denominado así por su cercanía a un manantial de agua procedente presumiblemente de los acuíferos de la sierra de Estepa), más concretamente en la cooperativa olivarera que hoy da nombre al yacimiento (Getsemaní). En este sentido, algún ejemplo más reciente de la literatura existente sobre el hallazgo de estas cuevas habla de la siguiente manera:

Donde hoy se levanta la cooperativa de aceitunas "Getsemaní", en la ladera sur del Cerro del Ojo, existió un conjunto de sepulturas calcolíticas (en torno a una veintena) excavadas en la roca. Todas ellas fueron destruidas al construir el establecimiento a comienzos de los años 80 del siglo pasado. Las tumbas poseían un lecho de piedras sobre el que se depositaron los restos óseos, algunos pintados de ocre, y ofrendas (vasos cerámicos y piezas de sílex). Se equipara a los enterramientos en cuevas artificiales documentados en su entorno (El Negrón y Juan Corrales, Gilena) (Camacho 2003: 12).

Del mismo modo, en el corpus de cuevas artificiales que Encarnación Rivero Galán recoge en su tesis doctoral (Rivero 1988: 74-75) y en el trabajo redactado por Rosario Cabrero (Cabrero 1985), las estructuras fúnebres halladas y arrasadas en el yacimiento arqueológico de Cerro del Ojo quedan descritas como espacios funerarios hipogeos con cámara sepulcral de $2 \mathrm{~m}$ de diámetro y 1'50 de alto, a la que se accedía mediante un corredor de $0^{\prime} 50 \mathrm{~m}$ de ancho y longitud imprecisa. Ya dentro de la cámara se encontrarían una serie indeterminada de inhumaciones acompañadas de un rico ajuar formado por láminas de sílex, piedras pulimentadas (hachas, azuelas), diversas formas cerámicas, etc. (Cabrero 1985; Rivero 1988: 74-75). Con el paso de los años, las distintas construcciones que en este lugar se han seguido realizando sin control de ningún tipo han dado al traste con similares restos patrimoniales, que hubieran supuesto un significativo avance en el desarrollo de la investigación y el conocimiento arqueológico de la zona en este periodo prehistórico concreto.

De igual forma, otra de las cuestiones que nos plantean ciertas dudas es la relativa a la posición que debieron adoptar los cuerpos en el momento en el que se procedió a su enterramiento. Aunque por diversas razones, ya expuestas anteriormente, las inhumaciones documentadas en Getsemaní-Cerro del Ojo han sido interpretadas como secundarias, no podemos descartar que fueran primarias (excepto la acumulación oriental del nicho este) debido a la alteración que en la posición de los restos óseos han provocado una serie de causas postdeposicionales, como las ocasionadas por los desprendimientos de tierra procedentes de las bóvedas y la variación que en ellos han podido suponer las numerosas raíces que encontrábamos en el interior de los nichos e incluso de los restos óseos humanos que allí descansaban. Así pues, aunque seguimos defendiendo nuestra hipótesis inicial que señala que los huesos, como parte del ritual, se depositan en su tumba definitiva una vez que estos, de un modo u otro, han perdido sus tejidos blandos y han sido pintados en ocre cinabrio, planteamos también la posibilidad de que los cuerpos fueran enterrados en posición accroupi, es decir, en vertical y en cuclillas, con las rodillas flexionadas y los glúteos pegados a los talones. Es esta, por tanto, la explicación que consideraríamos más plausible para que los huesos, como ya indicamos en el capítulo anterior, se encontraran agrupados de forma aparentemente aleatoria o desorganizada.

En cuanto a las referencias y paralelos que localizamos en este tipo de enterramientos, poco o nada nos pueden aportar al respecto, ya que encontramos multitud de formas (posición secundaria, fetal, flexionados, accroupi, decúbito lateral, en círculo, en cruz, cremados, introducidos en vasijas y otras tantas formas) que no hacen más que confirmar la heterogeneidad que muestran estas sociedades prehistóricas a la hora de establecer su ritual de enterramiento (Rivero 1988).

Otra de las cuestiones que han llamado poderosamente nuestra atención y creemos digna de mención, 


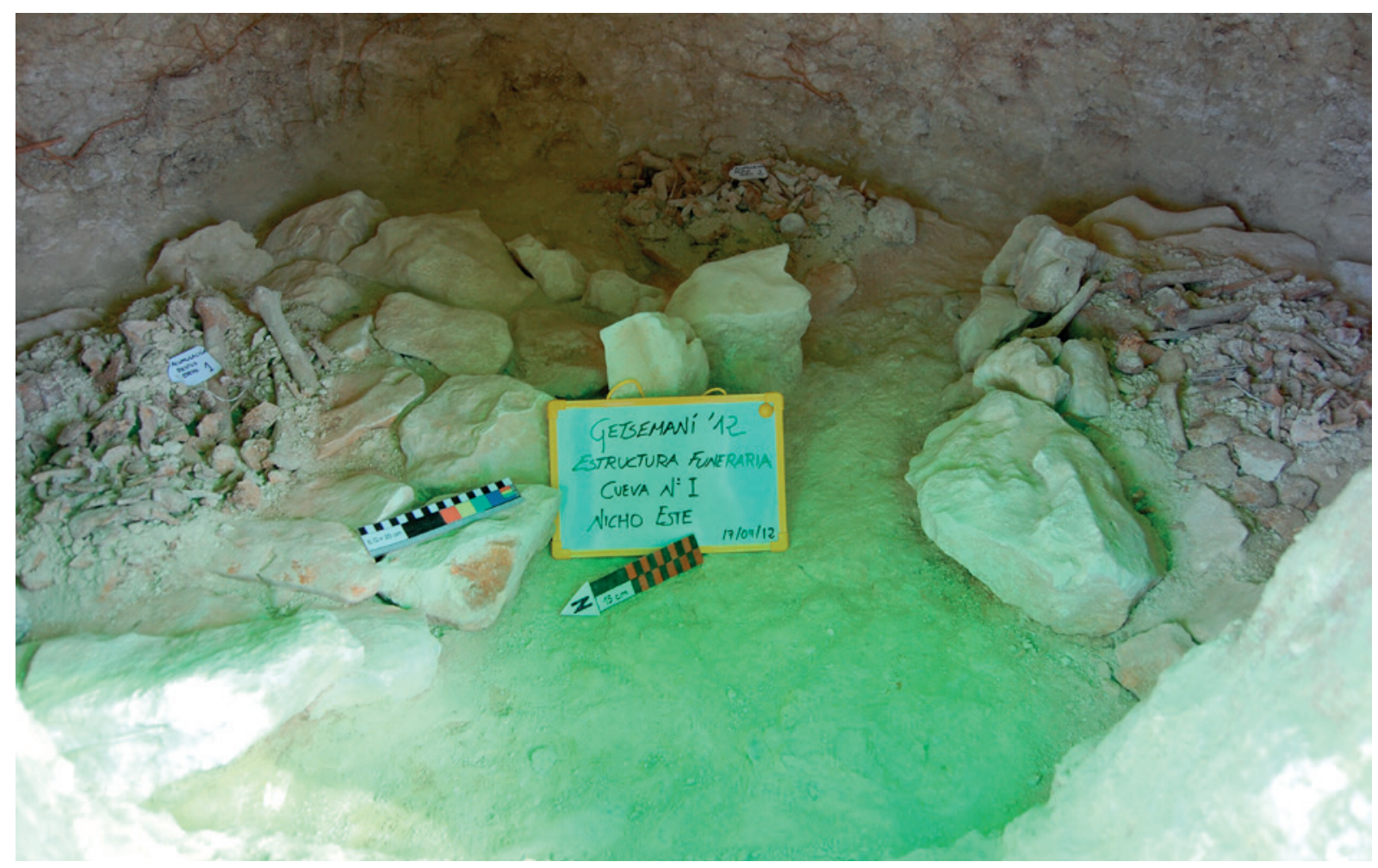

Figura 12: Vista general de los lechos y restos óseos hallados en el interior del nicho este (excavación concluida).

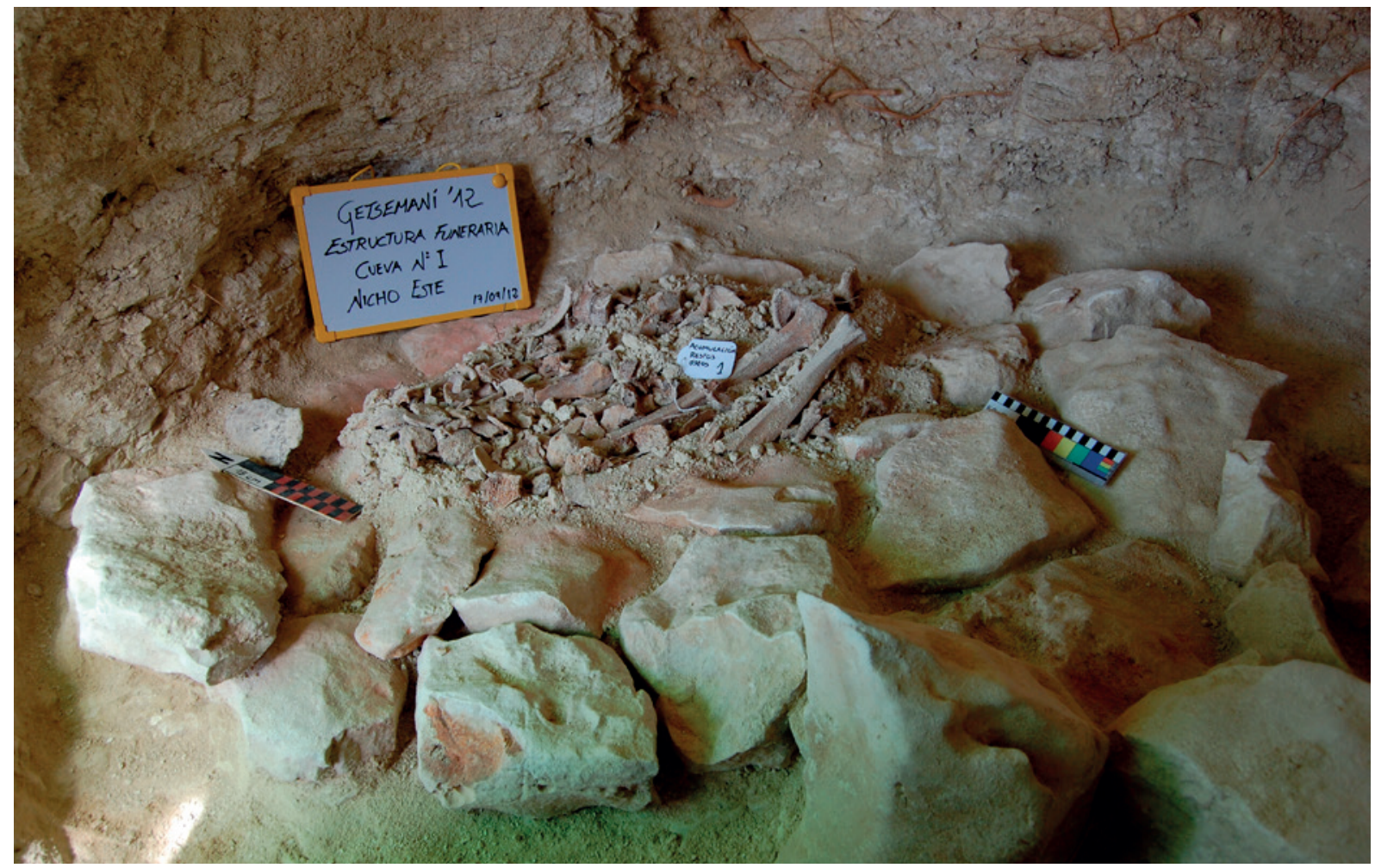

Figura 13: Vista en detalle de los restos óseos hallados sobre el lecho norte del nicho oriental. 
por su posible importancia dentro del ritual funerario empleado en la inhumación de los cuerpos, es la utilización del pigmento ocre rojo cinabrio en elementos constructivos (lechos), restos óseos inhumados y elementos de ajuar (gran lámina de sílex).

El uso de ocres con fines rituales o cultuales está documentado en Europa desde el periodo Paleolítico (Alimen y Steve 1977: 50), siendo las explotaciones de estos ocres las labores mineras de mayor antigüedad (Shepherd 1980: 210; Wagner y Weisgerber 1988: 265). En la península ibérica, los estudios orientados a concretar la naturaleza y composición de estas sustancias han permitido retrotraer el uso del cinabrio como material colorante en el área del Levante hasta los inicios del Neolítico, documentando el procesado y almacenamiento de ocre en yacimientos de esta misma cronología (García et al. 2006) y posteriores (el uso del ocre rojo cinabrio se documenta también en yacimientos del Cobre, Bronce e Hierro, manteniéndose así su utilización de forma ininterrumpida a lo largo de gran parte de la Historia). Aplicaciones a las que pudieron destinarse sustancias como los óxidos de hierro o el sulfuro de mercurio, tales como el dibujo parietal, el maquillaje corporal, la decoración de la cerámica, la protección de cueros y el secado de pieles o la tinción de tejidos, entre otras (Briceño 2011), explican el esporádico hallazgo en contextos domésticos de recipientes y utensilios implicados en su almacenamiento, procesado y aplicación, aunque será fundamentalmente en el registro funerario donde estos colorantes (básicamente rojizos) se encuentran más y mejor representados. En cuanto a su utilización en este tipo de contextos, ya a principios del siglo XX, los hermanos Siret (Siret 1905) y J. Furgús (Furgús 1937) dejaron esencialmente formuladas las dos principales hipótesis que han tratado de explicar la presencia de huesos coloreados en las sepulturas prehistóricas, pese a que, desde entonces, este tema se ha retomado y planteado de forma recurrente en bibliografía más actual (Delibes 2000: 227; Martínez 1984: 33).

Para los hermanos Siret estas pigmentaciones eran el resultado de la migración a los huesos de las sustancias colorantes empleadas en la tinción de telas, sudarios o prendas de vestir, con las que estaban ataviados los difuntos en el momento de producirse su enterramiento (Siret y Siret 1890). La tinción de partes del esqueleto no tendría un carácter intencional (o al menos no con un sentido particularmente simbólico, relacionado con el propio enterramiento), sino que se debería a las reacciones químicas ligadas al complejo proceso de putrefacción del cadáver y descomposición de su indumentaria en el interior de la sepultura. En este sentido, J. Carrasco Rus defiende esta misma teoría (Carrasco 1979: 272) indicando también que la descomposición de la tela durante la putrefacción del cadáver habría terminado por fijar a la superficie de los huesos que estaban en contacto con ella las sustancias utilizadas en su teñido.

La segunda hipótesis defendía que la impregnación en ocre de los huesos sería el resultado de un tratamiento post-mortem que consistía en colorear parcial o completamente el esqueleto, siendo, por tanto, un efecto ritual buscado intencionalmente. Así pues, el investigador Furgús se convirtió en un acérrimo defensor de esta hipótesis, asumiendo sin sutilezas que los cuerpos debían haber sido descarnados, cuando no previamente cremados, para ser después coloreados antes de su depósito en la tumba (Furgús 1937: 55). Por otro lado, estudios más recientes, sin embargo, intentan explicar e interpretar este aspecto como rudimentarias prácticas de embalsamamiento que pretendían preservar de la putrefacción la integridad de los cadáveres (Delibes 2000).

Además de estas teorías que hablan sobre la variedad de causas y formas en las que pudieron emplearse tanto el ocre como el cinabrio, debemos añadir también el posible uso como maquillaje corporal que se transfirió a los huesos tras la putrefacción del cadáver, sin que de momento podamos determinar si tal maquillaje pudo o no estar relacionado con tradiciones funerarias que persiguieran expresamente la conservación o embalsamamiento de los cadáveres como proponía G. Delibes (Delibes 2000).

Respecto a la utilización de estos colorantes rojizos, otra propuesta bastante recurrente en la bibliografía y apoyada en no pocas referencias etnográficas ha incidido en la asociación simbólica del color rojo con la sangre, siendo utilizado como reconstituyente mágico que se aplicaba al difunto, y a veces a su ajuar, para adquirir la fuerza que le permitiera obtener una nueva vida (López et al. 2012: 287-288). Su reiterada presencia en contextos funerarios de diversas épocas y en muchas regiones del mundo se explica, por tanto, como un intento de recuperar para el cadáver un "aspecto vital" mediante la aplicación o espolvoreado de sustancias colorantes que le confirieran un tono encarnado. Así, insistiendo en esta idea, el color rojo se relaciona con la idea de resurrección, transformación o tránsito a una nueva vida (Fitzsimmons 2009: 82).

Tampoco han faltado los planteamientos que insisten en la vinculación del rojo con la feminidad, y en particular con las peculiaridades ligadas a las capacidades 


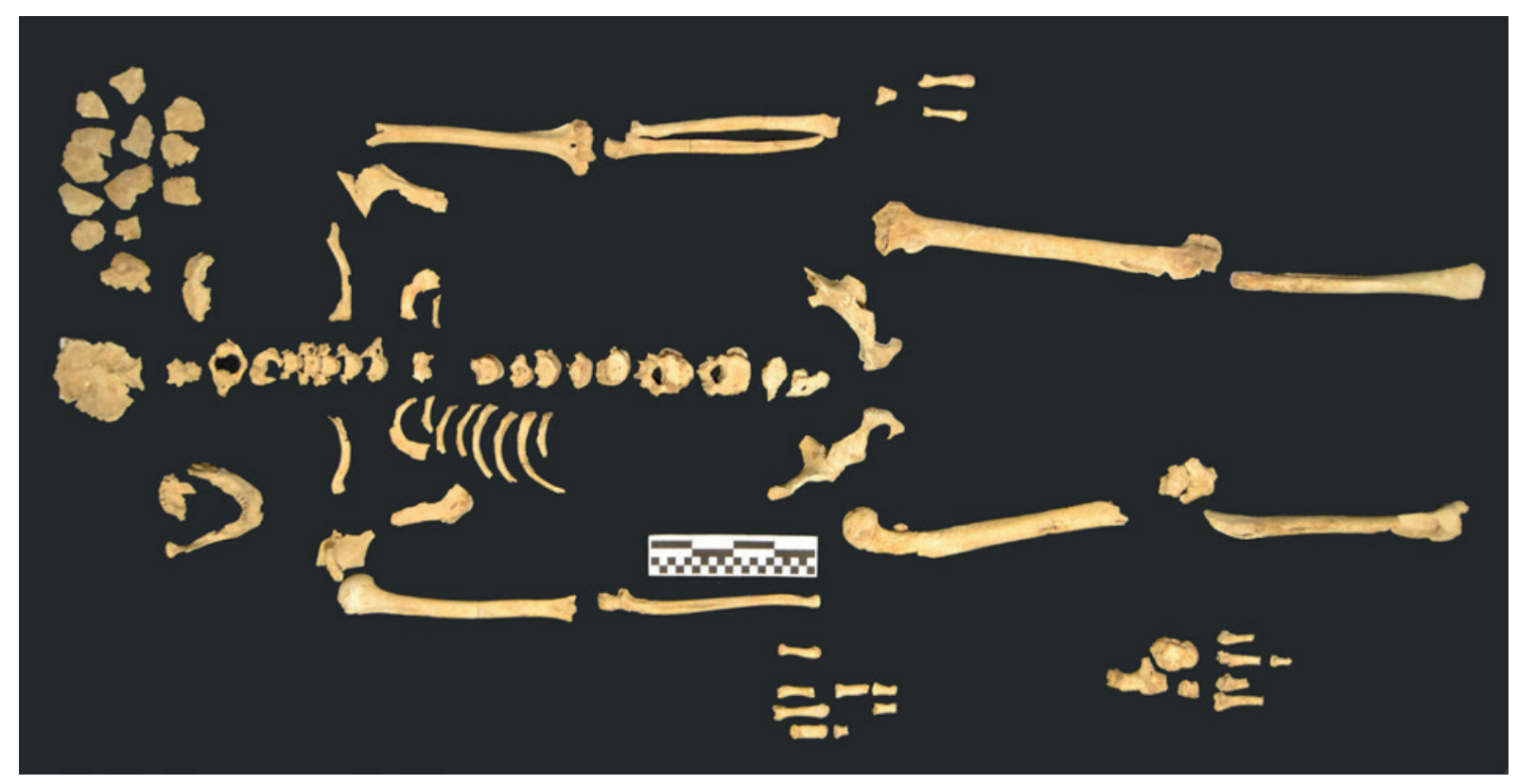

Figura 14. Restos óseos humanos que componen el esqueleto hallado sobre el lecho norte del nicho este (individuo 2.1).

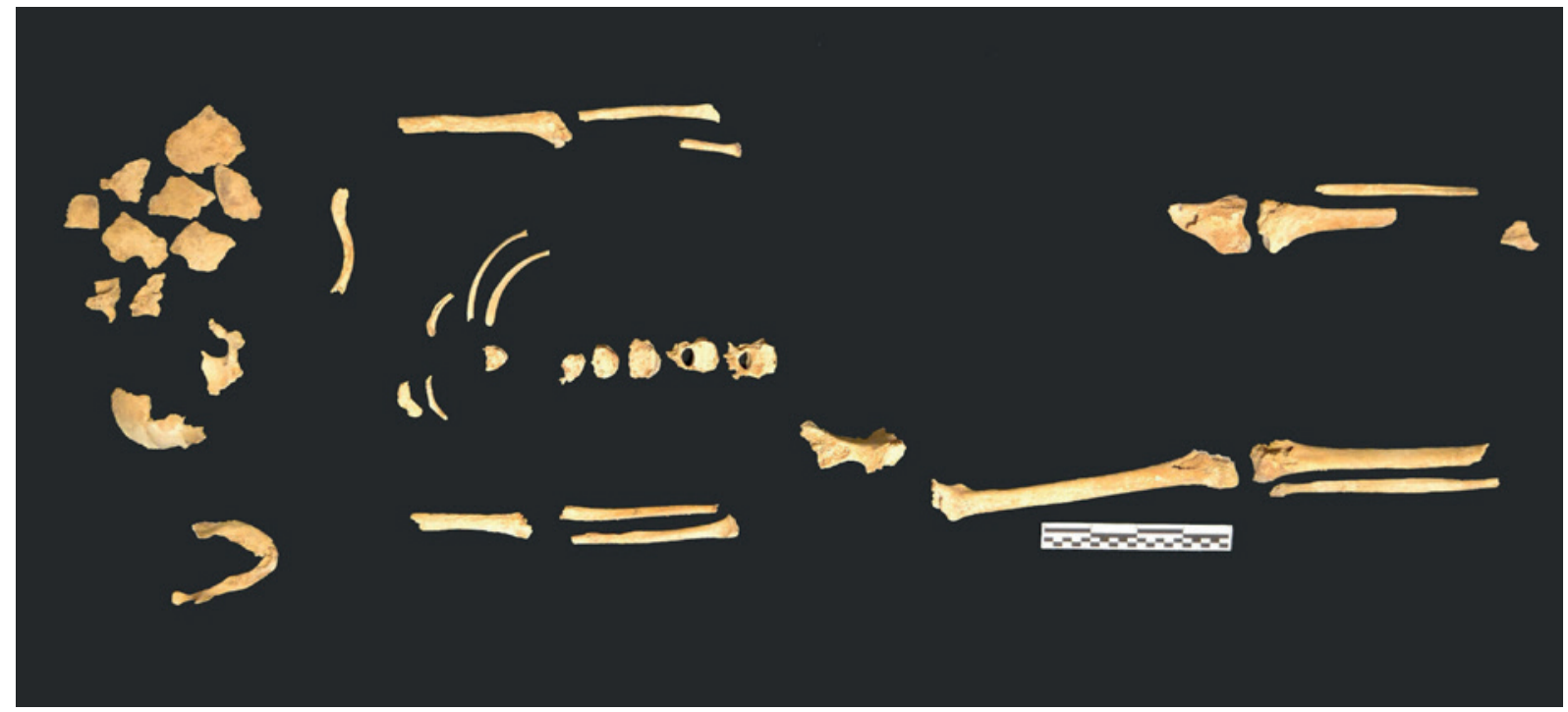

Figura 15. Restos óseos humanos que componen el esqueleto hallado sobre el lecho sur del nicho este (individuo 2.3).

reproductoras de la mujer y su ciclo menstrual. Así se ha explicado la presencia bien constatada de pigmentos rojizos sobre figurillas femeninas prehistóricas, como las denominadas "venus" de Grimaldi, Willendorf o Laussel (Petru 2006: 206). A este respecto debemos añadir que la teoría que relaciona los cuerpos pintados en rojo con féminas no se corresponde con la información extraída de nuestra intervención, puesto que hallamos lechos y huesos coloreados en ocre cinabrio en inhumaciones que corresponden a individuos de sexo claramente masculino.

Por suerte, cada vez es más habitual la publicación de estudios arqueométricos de muestras halladas en yacimientos calcolíticos de la Península, dejando atrás un vacío bibliográfico que resultaba cada vez más alarmante. Por ejemplo, investigaciones llevadas a cabo en la cueva del Cerro de Juan Barbero (Tielmes, Madrid) (Martínez 1984: 31; Rovira y Sanz 1984: 99-102), el 
Dolmen de Alberite (Villamartín, Cádiz) (Domínguez y Morata 1995: 140), La Velilla (Osorno, Palencia) (Martín et al. 1994; Delibes 2000), La Pijotilla y el Dolmen de Montelirio (Hunt y Hurtado 2009), las cuevas sepulcrales 1, 3 y 5 del valle de las Higueras (Huecas, Toledo) (Bueno et al. 2005), La Salmedina (Madrid) (Berzosa y Flores 2005) o las recientemente publicadas referidas a los contextos funerarios madrileños de Humanejos, Camino de las Yeseras, Cuesta de la Reina o La Magdalena (Ríos y Liesau 2011: 367, Tab. 3) han identificado ocres de diverso origen y también cinabrio como material colorante vinculado a huesos de esqueletos, piezas de ajuar o a espacios de carácter funerario. Con estos estudios de caracterización de materiales orientados a concretar la naturaleza y composición de estas sustancias se abren, por tanto, nuevas líneas de investigación que pueden arrojar cierta luz sobre los circuitos comerciales y redes de abastecimiento existentes en estas sociedades prehistóricas.

Respecto a las evidencias concretas de minería y uso del cinabrio, se ha constatado que uno de los yacimientos de mayor antigüedad en los que se ha confirmado el uso de cinabrio en la península ibérica es el Dolmen de Alberite (Villamartín, Cádiz), fechado en el $\mathrm{V}$ milenio a.C. y en que los pigmentos rojos cubrían parte de las paredes de la cámara y formaban un nivel rojo, de hasta $10 \mathrm{~cm}$ de potencia, en el suelo de algunas partes de la galería. El análisis de estos pigmentos por XRD (técnica de difracción de rayos $\mathrm{X}$ ) mostró que se habían utilizado tanto hematites $\left(\mathrm{Fe}_{2} \mathrm{O}_{3}\right)$, como cinabrio $(\mathrm{HgS})$, a veces mezclados en diversas proporciones. Se apuntaba que el cinabrio procedería de una distancia mínima de $200 \mathrm{~km}$ (Dominguez y Morata 1995: 141). También se ha constatado el uso ritual de pigmento rojo en el Dolmen de la Velilla (Osorno, Palencia), fechado en torno al 3000 a.C. En este caso se documentaron cientos de kilos de bermellón, producido mediante la trituración a polvo del cinabrio. Se consideró que la procedencia del mineral utilizado tuvo que ser necesariamente lejana, al encontrarse las mineralizaciones de cinabrio más próximas a $160 \mathrm{~km}$ de distancia (Martin et al. 1994; 1994a).

En la revisión de la bibliografía referida a intervenciones arqueológicas en yacimientos de carácter funerario del Suroeste peninsular de época calcolítica, las menciones al uso de "ocre" (como son denominados genéricamente los pigmentos rojos) son relativamente frecuentes, como ocurre en los tholoi de La Pijotilla (Badajoz) (Hurtado 1988: 46), en los dólmenes de Ontiveros y Montelirio de Valencina (Sevilla) (Vargas 2004: 51-52), en Los Molares (Sevilla) (Cabrero et al.
1996: 193) y en los dólmenes de El Pozuelo (Huelva) (Cerdán et al. 1952: 86). Además de las menciones genéricas al uso de ocre, también hay referencias expresas al uso de cinabrio, como en el dolmen de Matarrubilla, en la provincia de Sevilla (Obermaier 1919: 62) y, más recientemente y determinado analíticamente, en las tumbas E-2, E-3 y E-4 de la necrópolis calcolítica (III milenio a. C) de Paraje de Monte Bajo (Alcalá de los Gazules, Cádiz) (Lazarich 2007; Lazarich et al. 2009). De este modo, tomando como referencia otros estudios similares (Hunt y Hurtado 2010) como primer paso para determinar la posibilidad de establecer la procedencia de los pigmentos de cinabrio recuperados en el yacimiento arqueológico de Getsemaní-Cerro del Ojo, se ha llevado a cabo una aproximación a la ubicación y características de los depósitos minerales que lo contienen en el sur de la península ibérica. Sin yacimientos conocidos en el sur de Portugal, en la franja geológica de Ossa Morena los únicos depósitos de cinabrio son los situados en la zona de Usagre (Badajoz) (Tornos y Locutora 1989). También en la provincia de Granada, en Las Alpujarras, se localiza otra de las áreas con mineralizaciones de mercurio del sur peninsular, aunque la mayor concentración de cinabrio del sur de la península ibérica se encuentra en la zona minera de Almadén (Ciudad Real). Así pues, podemos determinar que la detección de cinabrio en contextos arqueológicos alejados de los depósitos minerales permite deducir, a priori, la existencia de redes de abastecimiento de larga distancia de ese pigmento. En este sentido, sirvan de orientación los resultados isotópicos extraídos de otros estudios que determinan que el origen del cinabrio utilizado en los contextos arqueológicos funerarios calcolíticos de La Pijotilla (Badajoz) y del Dolmen de Montelirio (Castilleja de Guzmán, Sevilla) estaría en el distrito minero de Almadén (Ciudad Real) (Hunt Ortiz 2010: 131).

Por otro lado, el hecho de no encontrar hábitat o poblados asociados a este recinto funerario hace aún más complicado, si cabe, determinar las relaciones parentales que pudieran haber existido entre los distintos individuos que se hallaban inhumados en los diferentes nichos que conforman la cueva artificial excavada en el yacimiento arqueológico de Getsemaní-Cerro del Ojo. De este modo, se antoja sumamente complicado precisar si la presencia de varios tipos de nichos y el enterramiento en ellos de unos u otros individuos responde a una cierta jerarquización social/familiar $u$ otro tipo de connotación cultural. Lo que sí podríamos descartar, casi con total seguridad, es que su vinculación al espacio de enterramiento sea sexualmente discriminatoria 


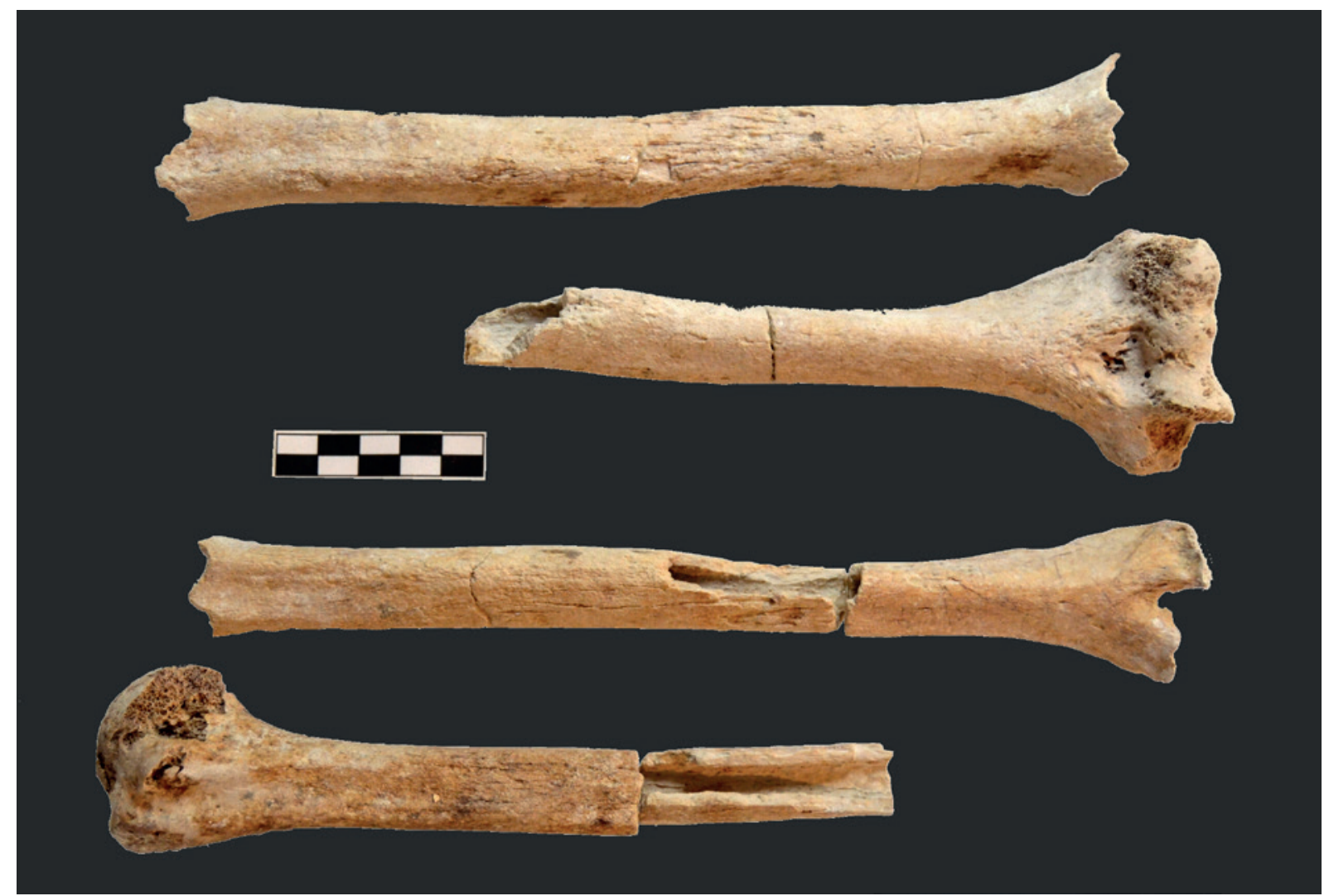

Figura 16: Parejas de húmeros correspondientes a los restos óseos humanos de los al menos dos cuerpos exhumados del lecho oriental del nicho este (individuos 2.2).

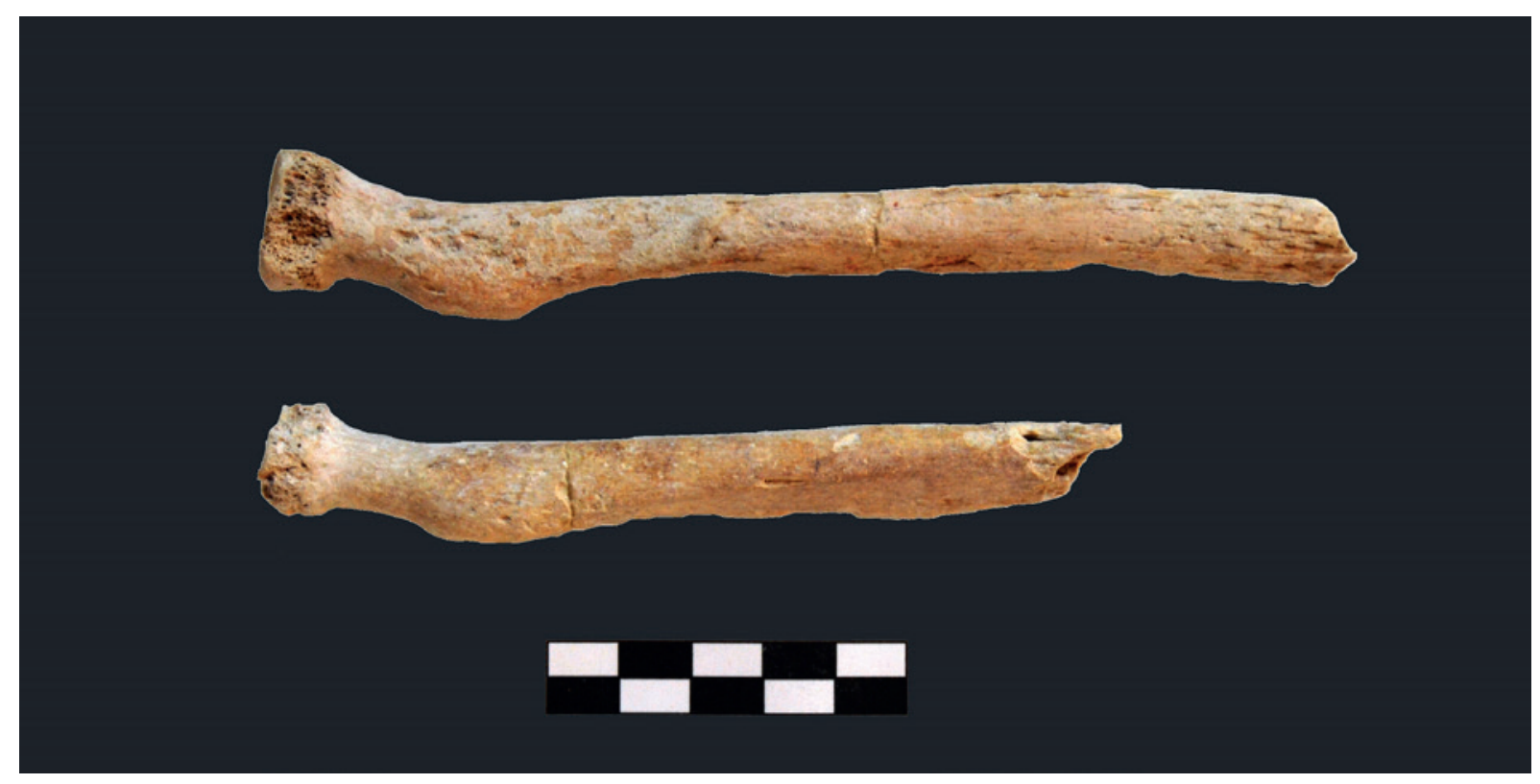

Figura 17. Restos óseos humanos correspondientes a radios de una misma lateralidad. Elementos que evidencian que son más de uno los individuos inhumados en el lecho este del nicho oriental (individuos 2.2).

ISSN: 1133-4525 ISSN-e: 2255-3924 
ya que en un mismo nicho (nicho oriental) hemos logrado identificar los restos óseos de individuos de sexo femenino compartiendo tumba con los de sexo masculino (los enterramientos, por tanto, pueden ser mixtos).

En lo que a tipología arquitectónica y constructiva se refiere, poco más podemos precisar de lo que se ha dicho hasta el momento, ya que el estado incompleto en el que hallamos la estructura funeraria nos impide ratificar y aseverar diferentes cuestiones que podrían ser de sumo interés para el estudio de "la arquitectura de la muerte" en época calcolítica. Pese a ello no debemos ignorar que los diversos ejemplos de sepulturas en cuevas artificiales son, generalmente, propios y característicos del Suroeste peninsular, encontrándose, hasta el momento, una mayor concentración de ellas en las provincias de Huelva, Sevilla, Córdoba y la región del Algarve y la Estremadura portuguesa. Así pues, dentro de estas diversas tipologías hallamos enterramientos siliformes como los de Campo Real en Carmona (Sevilla), mixtos (compuestos por mitad megalito mitad cueva artificial) como la que encontramos en la Sima de Castellar de Santisteban en Jaén y en el paraje de Monte Bajo en Alcalá de los Gazules en Cádiz (Lazarich 2007; Lazarich et al. 2009), o más similares a las que hallamos en el yacimiento de Cerro del Ojo (Cabrero 1985; Rivero 1988: 74-75), actual Getsemaní, con corredor de acceso o pozo de entrada como las de Alcaide I, II, III, IV, V, VI y VII en Antequera (Márquez et al. 1992 y 2006; Rivero 1988: 60-65), las de Alameda (Rivero 1988: 199) o las existentes en los espacios funerarios de las Aguilillas en Campillos (Espejo et al. 2005) y Ardales (Espejo et al. 2005; Ramos et al. 1997), todas ellas en Málaga.

Similares también son las de Carenque I, II y III en Sintra (Lisboa) (Rivero 1988: 120-122), la del yacimiento de La Calva en Santaella (Godoy 1989) o las de la finca La Beleña en Cabra (Córdoba) donde, además de las estructuras funerarias ya descubiertas en los años 80 (Moreno 2004; García y García 1983), durante el verano de 2015 se ha hallado de forma fortuita una tumba más cuya excavación ha corrido a cargo de un equipo de investigación de la Universidad de la Laguna (Tenerife), dirigido por la profesora María Dolores Camalich Massieu y el catedrático de Prehistoria Dimas Martín Socas (en prensa). A las cuevas artificiales ya enumeradas debemos sumar también las excavadas durante los años 2003 y 2004 en el yacimiento de La Molina, en Lora de Estepa (Juarez et al. 2008 y 2010) y las existentes en la vecina localidad de Gilena, Sevilla. Ejemplos de ellas serían las de Juan Corrales (Cabrero 1985; De la Hoz 1991) o las excavadas y recientemente restauradas en el yacimiento de El Negrón, Antoniana
I, II y III (Amores et al. 1987; Cruz-Auñón y Rivero 1987 y 1990; Cruz-Auñón et al. 1991, 1992, 1995 y 2015; Cruz-Auñón y Mejías 2009; Rivero 1988). Ya por último, también en la provincia sevillana, debemos mencionar, por la importancia que sus hallazgos han supuesto para las investigaciones sobre el mundo funerario prehistórico, las localidades de Valencina de la Concepción y Castilleja de Guzmán, donde además de sus ya conocidas estructuras dolménicas o tholoi, destacan una serie de cuevas artificiales que se encuentran situadas en las localizaciones denominadas: El Algarrobillo (Santana 1993; Pajuelo et al. 2013), Calle Dinamarca 3-5 (Pajuelo 2009; Pajuelo y López 2013; Pajuelo et al. 2013) y La Huera (Méndez 2013; Pajuelo et al. 2013).

Aunque muchas de estas estructuras funerarias de uso múltiple o colectivo tienen sus inicios en el Neolítico y siguen en uso durante la Edad del Bronce, caracterizándose por el funcionamiento sucesivo en el tiempo con posibilidad de reutilizaciones de un mismo espacio funerario (Cruz-Auñón et al. 2015: 78; Juarez et al. 2010: 214), gran parte de estas cuevas artificiales, aunque no todas (Lazarich 2007; Lazarich et al. 2009; Espejo et al. 2005; Ramos et al. 1997; Godoy 1989), han sido enmarcadas en un Calcolítico Pleno o Precampaniforme (Amores et al. 1987; Cruz-Auñón y Rivero 1987 y 1990; Cruz-Auñón et al. 1991, 1992, 1995 y 2015; Cruz-Auñón y Mejías 2009; Cabrero 1985; Rivero 1988; Moreno 2004; Juarez et al. 2008 y 2010; De la Hoz 1991; Santana 1993; Pajuelo et al. 2013; Pajuelo 2009; Méndez 2013) que se emplaza, al menos entre la cuenca media del Guadiana y el suroeste de la península ibérica, en unas fechas anteriores al 2700-2500 cal a.n.e. (García Rivero 2009: 240; 2006: 97; Lazarich 2005: 367). Sin embargo, las dataciones obtenidas en yacimientos del centro peninsular confirman la implantación del fenómeno Campaniforme en unas fechas algo más tardías; desde mediados del III milenio a.C. y prolongándose, en su modalidad de estilo Ciempozuelos, hasta el final del primer cuarto del II milenio a.C. como un fenómeno paralelo al surgimiento de las primeras comunidades de la Edad del Bronce en la zona (Ríos et al. 2012: 195)

De este modo, una vez analizadas las analogías y relaciones existentes entre algunos de los ejemplos ya citados y la estructura excavada recientemente en el yacimiento de Getsemaní-Cerro del Ojo, podemos insertar nuestro hallazgo en este contexto cronocultural que antecede a la expansión de la cultura Campaniforme en el suroeste peninsular, aportando una cronología que se sitúa próxima al primer cuarto del III milenio a.n.e. 


\section{Agradecimientos}

Queremos mostrar nuestro más sincero agradecimiento a D. Álvaro Caballero Amores, profesor-doctor del Departamento de Química Inorgánica e Ingeniería Química de la Universidad de Córdoba, por la realización del análisis y estudio de caracterización de materiales de las muestras de pigmento recogidas durante el desarrollo de la actividad arqueológica. Asimismo, debemos reconocer el apoyo prestado por nuestro colega Manuel Camacho Moreno en la consecución de alguna bibliografía específica de interés ciertamente difícil de localizar.

Por último, expresamos nuestra gratitud hacia todas aquellas personas e instituciones que han hecho posible la ejecución de este trabajo; especialmente a los distintos técnicos de la Delegación Provincial de Cultura en Sevilla que han visitado el yacimiento durante la realización de las labores arqueológicas y al Ayuntamiento de Gilena, especialmente a David Ruiz García, arqueólogo municipal y conservador de la Colección Museográfica de Gilena (CMG), por permitirnos la visita al yacimiento de El Negrón y mostrarnos su ayuda permanentemente. También al Ayuntamiento y habitantes de la localidad sevillana de Pedrera, a la S.C.A Getsemaní y a la empresa de servicios de ingeniería agronómica Cotecnisur S.L. por su interés y sensibilidad hacia la disciplina y ciencia arqueológica además de por su comprensión, paciencia, confianza y compromiso mostrado ante nuestra persona, empresa y profesión.

\section{BIBLIOGRAFÍA}

Alimen, M. H. y Steve, M. J. (1980): Prehistoria (Vol.I). Historia Universal Siglo XXI. Madrid. Ed. Siglo Veintiuno.

Amores Carredano, F. et al. (1987): “Actuación de urgencia en la cueva artificial de Antoniana (Gilena, Sevilla). Anuario Arqueológico de Andalucía/1985, vol. III: 270-273. Santander, Junta de Andalucía.

Bandera, Ma . L. Romo, A. S., Sierra, F. y Vargas, J.M. (1989): "Cerro Gordo, un yacimiento orientalizante de la Sierra Sur sevillana (Gilena, Sevilla)". Habis 20: 293-306.

Berzosa del Campo, R. y Flores Díaz, M. (2005): “El conjunto funerario campaniforme del Vertedero de La Salmedina (Distrito Villa de Vallecas, Madrid)", en M. A. Rojo Guerra; R. Garrido Pena y García Martínez de Lagrán (coords.), El Campaniforme en la Península Ibérica y su contexto europeo: 481490. Valladolid, Universidad de Valladolid.
Briceño Briceño, E. M. (2011): "La versatilidad de los colorantes minerales rojos en la Prehistoria reciente: Andalucía Occidental", en J. Abellán; C. Lazarich y V. Castañeda (dirs.), Homenaje al Profesor Antonio Caro Bellido I. Prehistoria y Protohistoria de Andalucía y Levante: 39-60. Cádiz, Universidad de Cádiz.

Bueno Ramírez, P.; Barroso Bermejo, R. y De Balbín Behrmann, R. (2005): "Ritual campaniforme, ritual colectivo: La necrópolis de cuevas artificiales del Valle de Las Higueras, Huecas, Toledo". Trabajos de Prehistoria 62 (2): 67-90. doi: 10.3989/tp.2005. v62.i2.69.

Cabrero García, R. (1985): "Las necrópolis de Cuevas Artificiales de Juan Corrales (Gilena) y Cerro del Ojo (Pedrera) en la provincia de Sevilla". Prehistoria 3: 1-26 Sevilla.

Cabrero García, R.; Ruiz Moreno, M.T.; Sabaté Díaz, I. y Cuadrado Martín, L.B. (1996): “Artefactos de tradición Neolítica en Sociedades Prehistóricas en la provincia de Sevilla: Cronología y Cambio Cultural", en Actas del I Congreso del Neolític a la Península Ibérica Vol. I: 191-200. Gavá-Bellaterra, (Barcelona, 1995). Rubricatum I, Vol. 1:191-200.

Camacho Moreno, M (2003): "Revisión y Actualización del Inventario de Yacimientos Arqueológicos de los Términos Municipales de Aguadulce, Gilena, Pedrera y La Roda de Andalucía en la provincia de Sevilla". Código de prospección: PTMPD-03-18. Delegación de Cultura de Sevilla. Junta de Andalucía (Sin publicar).

Carrasco Rus, J. (1979): “Algunas cuestiones acerca de la Cultura Argárica en la provincia de Granada”, en XV Congreso Nacional de Arqueología: 265-277. Lugo (1977), Zaragoza.

Cerdán Marquez, C.; Leisner, G. y Leisner, V. (1952): Los Sepulcros Megalíticos de Huelva. Informes y Memorias 26. Madrid, Ministerio de Educación Nacional.

Cruz-Auñón, R. y Mejías García, J.C (2009): “Sistemas de Información Geográfica y Análisis Espacial intrasite aplicados al estudio de la dispersión del registro arqueológico en la Necrópolis del III milenio a.n.e. de El Negrón (Gilena, Sevilla)", en Estudios de Prehistoria y Arqueología en Homenaje a Pilar Acosta Martínez. Serie Historia y Geografía 145: 207-232. Sevilla, Secretariado de Publicaciones de la Universidad de Sevilla.

Cruz-Auñón, R. y Rivero Galán, E. (1987): “Prospección con sondeos en el yacimiento prehistórico de El Negrón (Sevilla)". Anuario Arqueológico de 
Andalucía/1986, vol. II: 175-179. Santander. Consejería de Cultura de la Junta de Andalucía.

Cruz-Auñón, R. y Rivero Galán, E. (1990): "Yacimientos del Negrón (Gilena, Sevilla) Campaña 1987”. Anuario Arqueológico de Andalucía/1987, vol. II: 278-280. Santander. Consejería de Cultura de la Junta de Andalucía.

Cruz-Auñón, R.; Moreno, E. y Cáceres, P. (1991): "Campaña de 1989 en el yacimiento de El Negrón (Gilena, Sevilla)". Anuario Arqueológico de Andalucía/1989, vol. II: 315-320. Santander. Consejería de Cultura de la Junta de Andalucía.

Cruz-Auñón, R.; Moreno Alonso, E. y Cáceres Misa, P. (1992): "Estudio de materiales en el yacimiento de El Negrón (Gilena, Sevilla)". Anuario Arqueológico de Andalucía/1990, vol. II: $277-$ 280. Santander. Consejería de Cultura de la Junta de Andalucía.

Cruz-Auñón, R.; Moreno Alonso, E.; Cáceres Misa, P. y Valverde Lasanta, M. (1995): "Informe provisional de la excavación sistemática en el yacimiento de El Negrón (Gilena, Sevilla). Campaña de 1991”. Anuario Arqueológico de Andalucía/1992, vol. II: 347-352. Santander. Consejería de Cultura de la Junta de Andalucía.

Cruz-Auñón, R.; Mejías García, J. C., Pajuelo Pando, A. y López, P. M. (2015): “Apreciaciones en rituales funerarios de cuevas artificiales, Gilena un ejemplo", en Actas do II Congreso Internacional sobre arqueología de transição: 78-89. Évora, CHAIA (Centro de História de Arte e Investigação Artística) - Universidade de Évora.

De La Hoz, A. (1991): “Actuaciones arqueológicas en Gilena, 1988". Anuario Arqueológico de Andalucía/1988, 292-298. Santander. Consejería de Cultura de la Junta de Andalucía.

Delibes de Castro, G. (2000): “Cinabrio, huesos pintados en rojo y tumbas de ocre: ¿prácticas de embalsamamiento en la Prehistoria?", en M. Olcina y J. A. Soler (coords.), Scripta in honorem Enrique A. Llobregat Conesa: 223-236. Alicante, Instituto de Cultura Juan Gil-Albert.

Domínguez-Bella, S. y Morata Céspedes, D. (1995): “Aplicación de las técnicas mineralógicas y petrológicas a la arqueometría. Estudio de materiales del Dolmen de Alberite (Villamartín, Cádiz)". Zephyrus XLVIII: 129-142.

Espejo, M.; Ramos, J.; Cantalejo, P. y Martín, E. (1995): "Cerro de las Aguilillas. Necrópolis colectiva de cuevas artificiales". Revista de Arqueología 161: 14-23.
Espejo, M. Herrerías; Cantalejo Duarte, P.; Medianero Soto, J.; Aranda Cruces, A. y Maura Mijares, R. (2005): "Esculturas femeninas, masculinas y bisexuales del Tercer y Segundo milenio antes de nuestra era en la comarca del Guadalteba (Málaga)", en Actas de las I Jornadas de Patrimonio en la Comarca del Guadalteba: 223-228. Ardales, Bobastro.

Fabián García, J.M (1995): El aspecto funerario durante el Calcolítico y los inicios de la Edad del Bronce en el Sur de la Meseta Norte. El enterramiento colectivo en fosa de El Tomillar (Bercial de Zapardiel, Ávila) en su contexto cultural. Estudios Históricos y Geográficos 93. Salamanca, Ediciones Universidad de Salamanca.

Fernández Gómez, F.; Oliva Alonso, D. y Puya García de Leaniz, M. (1984): "La necrópolis tardorromana y visigoda de "Las Huertas" en Pedrera, Sevilla". Noticiario Arqueológico Hispánico 19: 272-288.

Fitzsimmons, J. L. (2009): Death and the Classic Maya Kings. Austin, University of Texas Press.

Furgús, J. (1937): Col·leció de treballs del P. J. Furgús sobre Prehistoria Valenciana. Treballs Solts 5. Valencia, Servei d'Investigació Prehistórica.

García Borja, P.; Domingo Sanz, I. y Roldán García, C. (2006): "Nuevos datos sobre el uso de materia colorante durante el Neolítico antiguo en las comarcas centrales valencianas". Saguntum 38: 49-60.

García García, J. y García Sánchez, M. (1983): “Un yacimiento eneolítico en Cabra (Córdoba)", en Actas I Congreso de Historia de Andalucía. Prehistoria y Arqueología: 49-51. Córdoba.

García Rivero, D. (2006): “Campaniforme y Territorio en la Cuenca Media del Guadiana". Spal 15: 71102. http://dx.doi.org/10.12795/spal.2006.i15.05

García Rivero, D. (2009): “Campaniforme, jerarquización social y selección interdémica en el suroeste de la Península Ibérica. Una aproximación desde la arqueología evolutiva”, en Estudios de Prehistoria y Arqueología en homenaje a Pilar Acosta Martínez: 233-254. Sevilla, Universidad de Sevilla.

García Sanjuán, L. (2013): “El asentamiento de la Edad del Cobre de Valencina de la Concepción: estado actual de la investigación, debates y perspectivas", en El Asentamiento Prehistórico de Valencina de la Concepción (Sevilla): Investigación y Tutela en el 150 Aniversario del Descubrimiento de La Pastora: 21-59. Sevilla, Secretariado de Publicaciones de la Universidad de Sevilla.

Godoy Delgado, F. (1989): "Excavación arqueológica de urgencia en el yacimiento de La Calva, Santaella (Córdoba)". Anuario Arqueológico de 
Andalucía 1986, vol. III: 127-131. Santander. Consejería de Cultura de la Junta de Andalucía.

Hunt, M.A. y Hurtado, V. (2010): "Pigmentos de sulfuro de mercurio - cinabrio- en contextos funerarios de época calcolítica en el Sur de la Península Ibérica: investigaciones sobre el uso, depósitos minerales explotados y redes de distribución a través de la caracterización composicional e isotópica", en M.E. Saiz; R. López; Mª.A. Cano y J.C. Calvo, (eds.), Actas VIII Congreso Ibérico de Arqueometría. Seminario de Arqueología y Etnología Turolense: 123-132. Teruel. Universidad de Zaragoza.

Hurtado Pérez, V. (1988): "Informe sobre las Campañas de Excavaciones en la Pijotilla (Badajoz)". Extremadura Arqueológica I: 35-54.

Juárez Martín, J. M.; Juárez Martín, J. M.; Moreno Alonso, E. y Cáceres Misa, P. (2008): “Intervención arqueológica de urgencia en la necrópolis prehistórica de cuevas artificiales de La Molina (Lora de Estepa, Sevilla)". Anuario Arqueológico de Andalucía/2004, vol. 1: 3326-3352. Santander. Consejería de Cultura de la Junta de Andalucía.

Juárez Martín, J.M.; Moreno Alonso, E.; Cáceres Misa, P.; Lacalle Rodríguez, R.; Guijo Mauri, J.M.; Nieto Liñán, J.M.; Aguilar Galea, J.A. y Rico Ramírez, E. (2010): El enterramiento en cueva artificial de la Molina (Lora de Estepa, Sevilla). Sevilla. Junta de Andalucía. Consejería de Cultura.

Lazarich González, M. (2005): "El Campaniforme en Andalucía”, en I. García-Martínez de Lagrán, R. Garrido Pena y M. A. Rojo (coords.), El campaniforme en la Península Ibérica y su contexto europeo: 351370. Valladolid. Universidad de Valladolid, Secretariado de Publicaciones e Intercambio Editorial

Lazarich González, M. (2007): La Necrópolis de Paraje de Monte Bajo (Alcalá de los Gazules, Cádiz). Un acercamiento al conocimiento de las prácticas funerarias prehistóricas. Cádiz, Universidad de Cádiz.

Lazarich González, M.; Valetín Fernández de la Gala, J.; Jenkins, V.; Peralta, P.; Briceño, E.; Ramos, A.; Richarte, M.J.; Carreras, A.M.; Núñez, M.; Versaci, M.; Stratton, S.; Sánchez, M. y Grillé, J.M. (2009): "Paraje de Monte Bajo (Alcalá de los Gazules). Una nueva necrópolis de cuevas artificiales en el Sur de la provincia de Cádiz”. Almoraima 39: 67-83.

Lopera Delgado, M.R. (1995): "El mundo funerario calcolítico en la provincia de Córdoba. Recopilación y actualización de los datos". Ariadna 15: 7- 48.

López Padilla, J.A.; Miguel Ibáñez, M.P.; Arnay de la Rosa, M.; Galindo Martín, L.; Roldán García, C. y Murcia Mascarós, S. (2012): “Ocre y cinabrio en el registro funerario de El Argar". Trabajos de Prehistoria 69 (2): 273-292. doi: 10.3989/tp.2012.12092

Marqués Merelo, I.; Ferrer Palma, J.E. y Márquez Romero, J.E. (1992): “Actuaciones en el yacimiento de Alcaide (Antequera, Málaga) durante la campaña 1990". Anuario Arqueológico de Andalucía/1990, vol. 1: 210-212. Santander. Consejería de Cultura de la Junta de Andalucía.

Marqués Merelo, I.; Aguado Mancha, T.; Baldomero Navarro, A. y Ferrer Palma, J.E. (2006): "Proyectos sobre La Edad del Cobre en Antequera (Málaga)". Simposios de Prehistoria II-III Cueva de Nerja: 238-260. Málaga, Fundación de Nerja.

Martín Gil, J.; Martin Gil, F.J.; Delibes de Castro, G.; Zapatero Magdaleno, P. y Sarabia-Herrero, FJ. (1994a): "Preserving the Ancients with Vermillion". The Lancet 344, no 8939/8940: 1776-1777.

Martín Gil, J.; Martín Gil, F.J.; Delibes de Castro, G.; Zapatero, P. y Sarabia, J. (1994b): "Neolítico. Uso del Cinabrio". Investigación y Ciencia 219: 29-30.

Martínez Navarrete, M. I. (1984): "El comienzo de la metalurgia en la provincia de Madrid: la Cueva y el Cerro de Juan Barbero (Tielmes, Madrid)". Trabajos de Prehistoria 41: 17-89. doi 10.3989/ tp.2012.12092.

Méndez, E. (2013): "La cueva artificial de La Huera (Castilleja de Guzmán)", en El asentamiento prehistórico de Valencina de la Concepción (Sevilla): Investigación y Tutela en el 150 Aniversario del Descubrimiento de La Pastora: 293-310. Sevilla, Secretariado de Publicaciones de la Universidad de Sevilla.

Moreno A. (2004): “Actualización y revisión de yacimientos arqueológicos de algunos términos municipales de la zona sur de la provincia: Cabra y Luque" (Informe Inédito). Archivo de la Delegación Provincial de la Consejería de Cultura, Córdoba.

Nocete, F. (2001): Tercer Milenio antes de nuestra era. Relaciones y contradicciones centro/periferia en el Valle del Guadalquivir. Barcelona, Bellaterra.

Obermaier, H. (1919): El Dolmen de Matarrubilla (Sevilla). Comisión de Investigaciones Paleontológicas y Prehistóricas. Memoria n ${ }^{\circ} 26$. Madrid, Museo Nacional de Ciencias Naturales.

Pajuelo, A. (2009): Excavación Arqueológica Preventiva en C/ Dinamarca 3-5. Urb. El Algarrobillo (Valencina de la Concepción). Sevilla. (Memoria inédita). Delegación Provincial de la Consejería de Cultura de la Junta de Andalucía. Sevilla.

Pajuelo, A.; López Aldana, P.M.; Cruz-Auñón Briones, R. y Mejías-García, J.C. (2013): "Las cuevas 
artificiales de Valencina. Análisis y propuestas de la distribución espacial a escala regional", en Actas VI Encuentro de Arqueología del Suroeste Peninsular: páginas. Villafranca de los Barros, Exmo. Ayto. de Villafranca de los Barros.

Pajuelo, A. y López, P.M. (2013): “La necrópolis de cuevas artificiales y fosas de c/ Dinamarca 3 y 5 (Valencina de la Concepción, Sevilla)", en El asentamiento prehistórico de Valencina de la Concepción (Sevilla): Investigación y Tutela en el 150 Aniversario del Descubrimiento de La Pastora: 281-292. Sevilla, Secretariado de Publicaciones de la Universidad de Sevilla.

Phenice, T. W. (1969): "A newly developed visual method of sexing in the os pubis". American Journal of Physical Anthropology 30 (2): 297-301.

Petru, S. (2006): "Red, black or white? The dawn of colour symbolism". Documenta Praehistorica 33: 203-208.

Polvorinos del Río, A.; HERNÁNDEZ, M.J.; ALMARZA, J.; FORTEZA, M.; CASTAING, J. y HURTADO, V. (2008): "Estudio Arqueométrico de las Láminas de Sílex procedentes de la Tumba III del yacimiento de La Pijotilla (Badajoz)", en $A c$ tas del VII Congreso Ibérico de Arqueometría: 379389. Madrid, CSIC, Instituto de Historia.

Ríos, P. y Liesau, C. (2011): "Elementos de adorno, simbólicos y colorantes en contextos funerarios y singulares", en C. Blasco; C. Liesau y P. Ríos (eds.): Yacimientos calcolíticos con campaniforme de la Región de Madrid: nuevos estudios. Patrimonio Arqueológico de Madrid 9: 357-370. Madrid. Universidad Autónoma de Madrid.

Ramos Muñoz, J.; Espejo Herrerías, M.M.; Recio Ruiz, A.; Cantalejo Duarte, P.; Martín Córdoba, E.; Durán Valsero, J.M.; Castañeda Fernández, V.; Pérez Rodríguez, M. y Cáceres Sánchez, I. (1997): "La necrópolis colectiva del Cerro de las Aguilillas (Ardales-Campillos, Málaga). Inferencias socioeconómicas". Revista Atlántica-mediterránea de Prehistoria y Arqueología Social 1: 150-180.

Ríos, P.; Blasco, C. y Aliaga, R. (2012): "Entre el Calcolítico y la Edad del Bronce. Algunas consideraciones sobre la cronología campaniforme". Cuadernos de Prehistoria y Arqueología, 37-38: 195-208. Universidad Autónoma de Madrid.

Rivero Galán, E. (1986): "Ensayo tipológico en los enterramientos colectivos denominadas Cuevas artificiales de la mitad meridional de la Península Ibérica". Habis 17: 371-402.

Rivero Galán, E. (1988): Análisis de las cuevas artificiales en Andalucia y Portugal. Sevilla, Universidad de Sevilla.
Rivero Galán, E. y Cruz-Auñón, R. (1990): “Excavación de urgencia en la cueva artificial de Los Corralones (Gilena, Sevilla)". Anuario Arqueológico de Andalucia/1988, vol. III: 374-376. Santander. Consejería de Cultura de la Junta de Andalucía.

Rovira Llorens, S. y Sanz Nájera, M. (1984): “Apéndice 2. Análisis de laboratorio de algunos materiales de la Cueva de Juan Barbero", en M. I. Martínez Navarrete, "El comienzo de la metalurgia en la provincia de Madrid: la Cueva y el Cerro de Juan Barbero (Tielmes, Madrid)". Trabajos de Prehistoria 41: 94-104. doi 10.3989/tp.2012.12092

Romo Salas, A. S.; Sierra Alonso, F. y Vargas Jiménez, J.M. (1990): "Prospección Arqueológica Superficial del Término Municipal de Gilena (Sevilla)". Anuario Arqueológico de Andalucía/1988, vol. III: 306-314. Santander. Consejería de Cultura de la Junta de Andalucía.

Santana, I. (1993): "Excavación arqueológica de urgencia en El Algarrobillo, Valencina de la Concepción (Sevilla)". Anuario Arqueológico de Andalucía/1991, vol. 1: 548-553. Santander. Consejería de Cultura de la Junta de Andalucía.

Serrulla, F. (coord.) (2013): Recomendaciones en antropología forense. Valdepeis: Asociación Española de Antropología y Odontología Forense.

Shepherd, R. (1980): Prehistoric Mining and Allied Industries. Londres, Academic Press.

Siret, E. (1905): "Note sur la communication du R.P. Furgús relative á des tombes préhistoriques a Orihuela". Annales de la Société d'Archéologie de Bruxelles XIX: 371-380.

Siret, E. y Siret, L. (1890): Las Primeras Edades del Metal en la Península Ibérica. Barcelona, Tipografía de Heinrich y Cía.

Todd, T. W. (1921): "Age changes in the pubic bone". American Journal of Physical Anthropology 4 (1): $1-70$.

Tornos, F. y Locutura, J. (1989): "Mineralizaciones Epitermales de Hg en Ossa Morena (Usagre, Badajoz)". Boletín de la Sociedad Española de Mineralogía, $\mathrm{n}^{\circ}$ 12: 363-374.

Ubelaker, D. H. (1989): Human skeletal remains. Washington, Taraxacum.

Vargas Jiménez, J.M. (2004): El yacimiento prehistórico de Valencina de la Concepción (Sevilla). Valencina de la Concepción, Ayuntamiento de Valencina de la Concepción.

VV.AA. (2006): Data Collection Codebook. The Global History of Health Project. Columbus, Ohio University. 
Wagner, G.A. y Weisberger, G. (eds.) (1988): Antike Edel- und Buntmetallgewinnung auf Thasos. Der Anschnitt, 6. Bochum, Deutschen BergbauMuseums.
White, T. y Folkens, P. (2005): The Human Bone Manual. Burlington, Elsevier Academic Press.

Workshop of European Anthropologists (1980): "Recommendations for age and sex determination". Journal of Human Evolution 9: 517-549. 